\title{
The classical case of character release: Darwin's finches (Geospiza) on Isla Daphne Major, Galápagos
}

\author{
P. T. BOAG* \\ Edward Grey Institute, Department of Zoology, \\ University of Oxford, Oxford OX1 3PS \\ AND P. R. GRANT \\ Division of Biological Sciences, University of Michigan, \\ Ann Arbor, Michigan 48109, U.S.A.
}

Accepted for publication 4 May 1983

The history of how Darwin's medium ground finch (Geospiza fortis) on Isla Daphne Major, Galápagos became a textbook example of character release is reviewed. Four hypotheses for the evolution of the intermediate-sized Daphne fortis are examined, including genetic drift/founder effect, hybridization with the small ground finch (G. fuliginosa), food supply (or local adaptation hypothesis) and character release in allopatry.

Modern data suggest that genetic drift is unlikely to have been important, due to inadequate isolation and over-riding selection and introgression on Daphne. All three remaining hypotheses have probably played a role. Hybridization with $G$. fuliginosa occurs, although it cannot counteract the selection pressures seen during our study. Local adaptation has also occurred, with natural selection changing the relative frequencies of fortis phenotypes in response to changes in Daphne food supplies. The selection resulted from correlations between the size of seeds available, feeding behaviour and morphology. However, recent phenotypic tracking has resulted in larger, not smaller phenotypes. There is also evidence for character release in the form of diet expansion by G. fortis during periods of food shortage, and indirect evidence for interspecific competition between fortis and the cactus ground finch ( $G$. scandens). The Daphne fortis phenotype probably represents a balance between introgression with fuliginosa, selection for larger body size in dry years and selection for smaller body size in wet years. The simple textbook account of a character shift caused by the accidental absence of competitors should be qualified to reflect the ecological complexity of the situation.

KEY WORDS:- Competition - Darwin's finches - Galápagos - Geospiza - granivory hybridization - morphometrics - natural selection.

\section{CONTENTS}

Introduction .

Historical interpretations of Daphne fortis morphology

Four hypotheses for the Daphne phenotype . . . . . . . 249

Methods

*Present address: Department of Biology, Queen's University, Kingston, Ontario, Canada.

$0024-4066 / 84 / 070243+45 \$ 03.00 / 0$ 


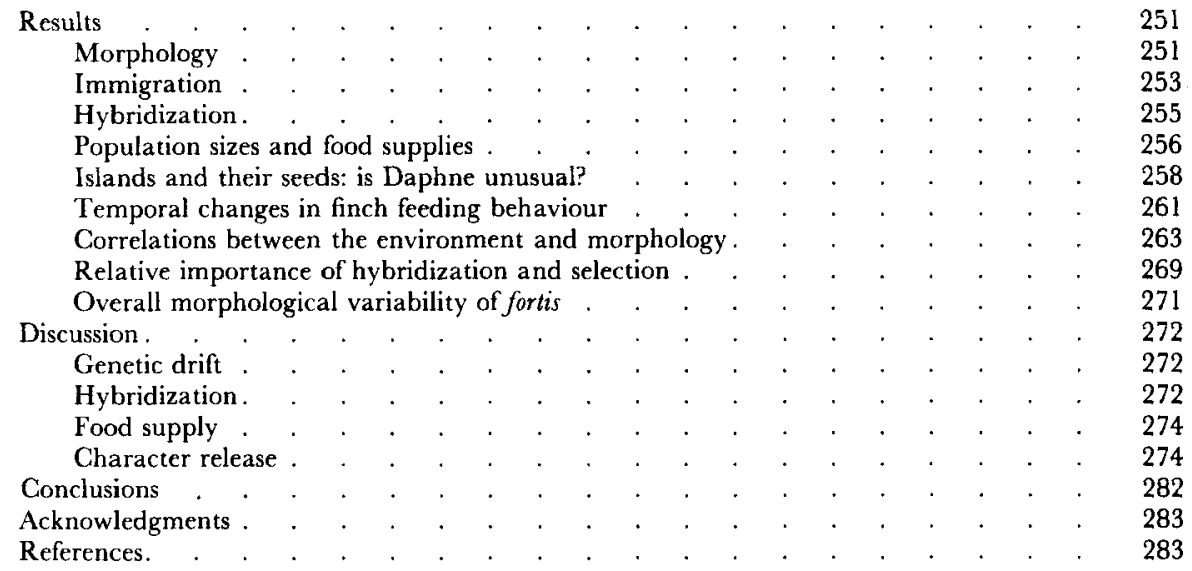

\section{INTRODUCTION}

The question of how interspecific competition has influenced the formation of animal communities has received widespread attention in recent years. But a cursory examination of textbooks on ecology, evolution, or general biology soon produces a short list of repeatedly cited examples of competition. One of these is David Lack's (1947) suggestion that the bill sizes of Darwin's ground finches (genus Geospiza) change from island to island in the Galápagos, depending on the presence or absence of larger or smaller congeners. Fig. 1 is a reproduction of Lack's (1947) illustration of this phenomenon (see also Simpson \& Beck, 1965: 649; Odum, 1971: 241; Colinvaux, 1973: 352; Ricklefs, 1973: 212; Welty, 1975: 521; Pianka, 1978: 323; Roughgarden, 1979: 11; Arthur, 1982: 153).

This diagram is usually presented as one of the best examples of competitionmediated character displacement. The medium ground finch (Geospiza fortis) and the small ground finch ( $G$. fuliginosa) display similar bill depths in allopatry on the islets of Daphne and Los Hermanos (four small islands, referred to as the "Crossmans" by Lack $(1945,1947))$. In sympatry with larger or smaller congeners on islands such as Santa Cruz (previously called Indefatigable), fortis is found higher on a scale of increasing bill depth while fuliginosa is displaced downwards (Figs 1, 2). The displacement is sometimes described as divergence in sympatry: "Competition between species in the same habitat promotes evolutionary divergence. Species of Geospiza living on the same island show greater divergence in beak form than the same species living on isolated islands where they need not complete" (Welty, 1975: 521). Elsewhere, the pattern is described as allopatric convergence: "Thus, each allopatric species converged towards the other, partially filling, as it were, the other niche" (Odum, 1971: 241).

Part of the difference in interpretation is related to Lack's $(1945,1947,1969)$ own uncertainty about the situation, but in large measure it reflects confusion over the terminology of character displacement. P. R. Grant (1972) suggested that the general term character shift be used to describe any change in a character of one species associated with the presence or absence of another species in the same environment. The more specific terms of divergent (or 


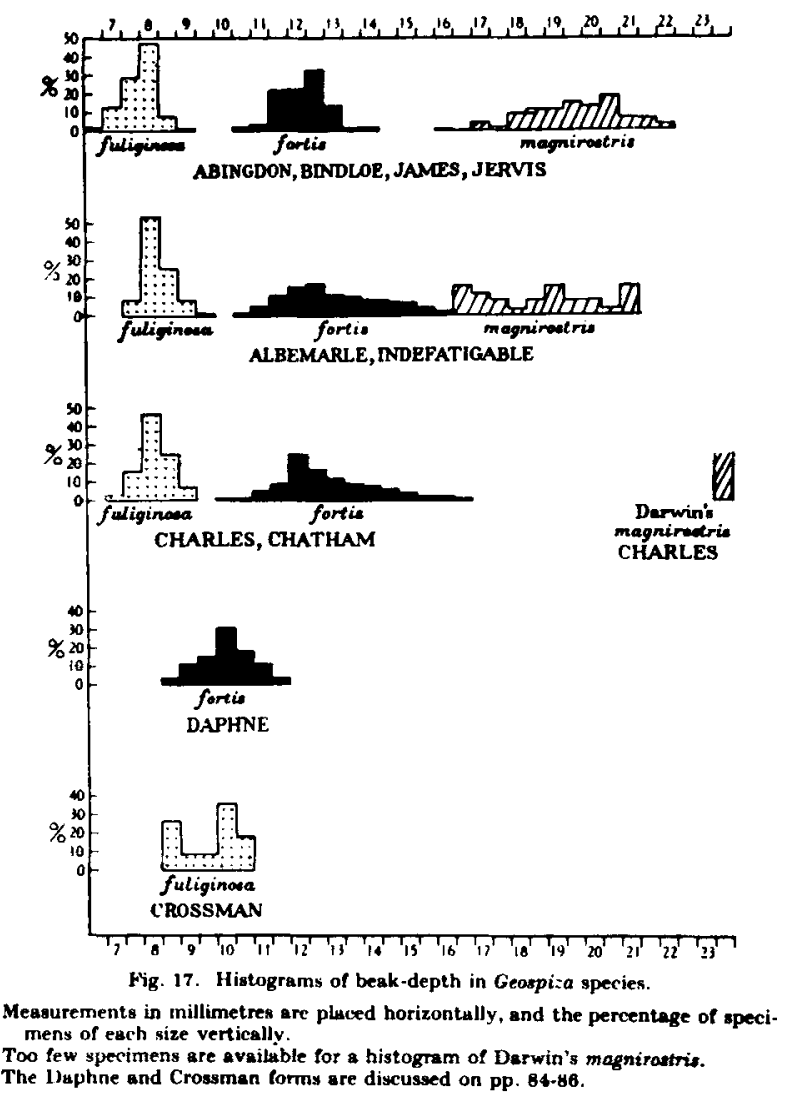

Figure 1. Illustration from Lack (1947) showing Geospiza bill depth distributions on Galápagos islands. Modern island names are provided in Fig. 2. (Reproduced with the permission of Cambridge University Press.)

convergent) character displacement and character release then refer to changes caused by the presence of another species and the absence of another species, respectively. Grant (1972) went on to point out that if one assumes that the Daphne and Hermanos populations were derived from surrounding Geospiza populations, both situations are examples of character release.

Thus Fig. 1 has been widely cited as a clearcut case of character release. Its apparently simple visual statement of the dynamic interaction between morphological and distributional patterns among avian congeners has proved attractive in explaining why vertebrate communities display regular patterns of non-overlapping morphologies among ecologically or phylogenetically related species (Pulliam, 1975; Horn \& May, 1977; Diamond, 1978; P. R. Grant, 1981a, 1983a; but see Simberloff \& Boecklen, 1981). Despite its intuitive appeal, a careful reading of Lack's $(1945,1947,1969)$ work reveals how little ecological data the illustration is actually based on, and added to this, most secondary references to this example gloss over the very real reservations and changes of opinion expressed by Lack in successive publications.

Since Lack's visit to the Galápagos in 1938-1939, many new data have been collected on the biology of Darwin's finches, and in the last decade our knowledge of the genus Geospiza and the Daphne Geospiza populations in 


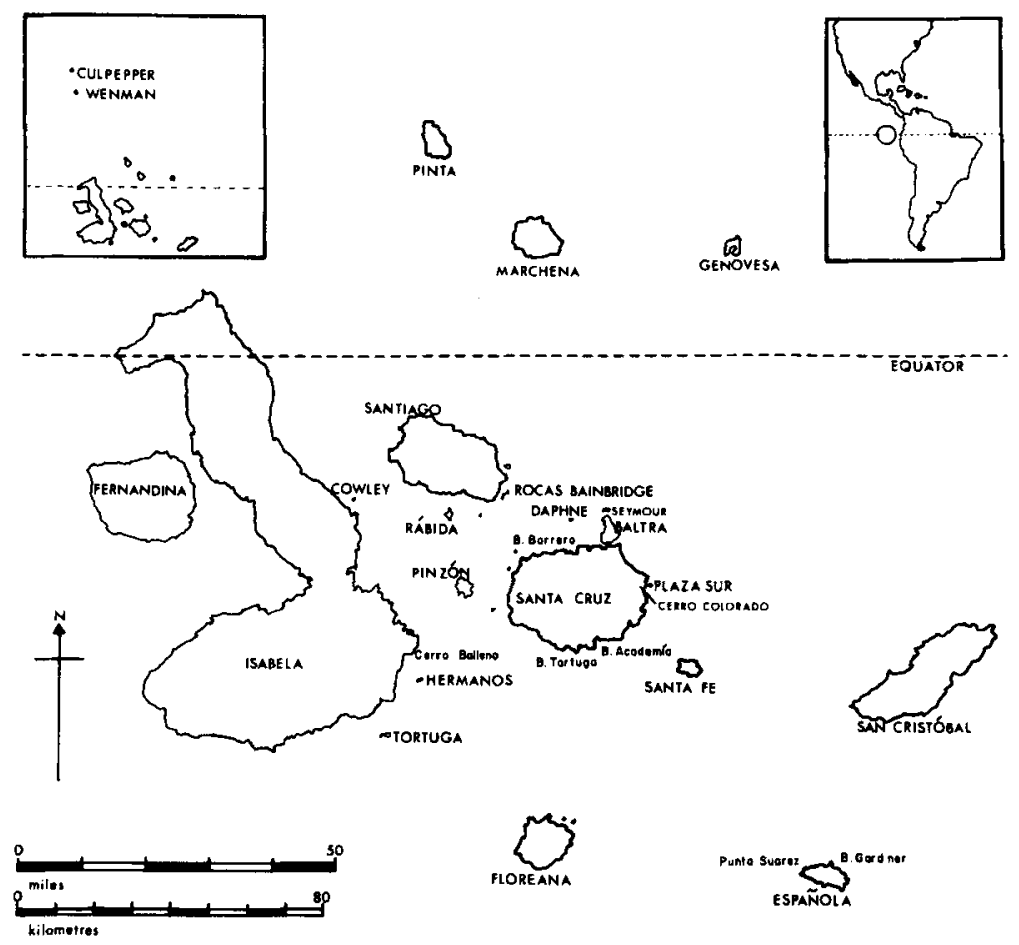

Figure 2. Map of the Galápagos. The Hermanos are a group of four islands, numbered I through IV. Prevailing winds from the south and east affect the relative isolation of finch populations on various islands. Older texts use the following names: Española $=$ Hood, Floreana $=$ Charles or Santa Maria, San Cristóbal = Chatham, Santa $\mathrm{Fe}=$ Barrington, Santa Gruz = Indefatigable, Pinzón $=$ Duncan, Rábida $=$ Jervis, Santiago $=$ James or San Salvador, Hermanos $=$ Crossmans, Isabela $=$ Albemarle,$\quad$ Fernandina $=$ Narborough,$\quad$ Marchena $=$ Bindloe,$\quad$ Pinta $=$ Abingdon, Genovesa $=$ Tower. (Map adapted from Harris, 1974.)

particular has increased enormously (P. R. Grant et al., 1975; Abbott, Abbott \& Grant, 1977; Smith et al., 1978; P. R. Grant \& B. R. Grant, 1980a; Boag \& Grant, 1981). The purpose of this paper is to re-examine the purported character shift on Isla Daphne Major. We do this by first examining the history behind the prominence of the Daphne example, and then by examining four alternative, though not mutually exclusive, hypotheses for how the intermediate Daphne fortis phenotype might have evolved. Some of our data on the effects of natural selection on the Daphne finches has been published in a preliminary form elsewhere (Boag \& Grant, 1981). Additional details of the Daphne field work may be found in Boag (1981) and Boag \& Grant (1984).

\section{HISTORICAL INTERPRETATIONS OF DAPHNE G. FORTIS MORPHOLOGY}

The morphological intermediacy of the Daphne and Hermanos populations has long been recognized. Ridgeway (1897) lumped both populations, along with similar Geospiza specimens of uncertain affinity, in the catch-all species Geospiza harterti. Swarth (1931) did away with $G$. harterti and reclassified the Daphne birds as small fortis and the Hermanos birds as large fuliginosa, a decision not disputed by subsequent taxonomists (Boag, 1981). In the initial 
description of his 1938-1939 Galápagos research, Lack (1945) felt that nonadaptive processes such as founder effect and genetic drift were crucial to an understanding of the evolution of the Galápagos finches. After quoting Darwin's famous passage,

how is it that many of the immigrants have been differently modified . . . in islands situated within sight of each other, having the same geological nature, the same height, climate, etc.? This . . difficulty . . . arises . . . from the deeply-seated error of considering the physical conditions of a country as the most important; whereas it cannot be disputed that the nature of the other species with which each has to compete, is at least as important ... (Darwin, 1888: 355-356, quoted by Lack, 1945: 117).

Lack (1945: 117) wrote: "There is no evidence in favour of Darwin's suggestion. In fact, there is no evidence whatever, in any of the island forms of Geospizinae, that their differences have adaptive significance". Although puzzled by the Daphne and Hermanos populations, Lack (1945: 90-96) pursured his non-adaptive reasoning by stating that "the populations on the extremely small islands of Daphne and Crossman [= Hermanos] seem to be intermediate in character between fuliginosa and fortis. . . The most probable explanation is that these forms have originated from a cross between fuliginosa and fortis".

In 1947 Lack rewrote his Galápagos research, as the now classic book Darwin's Finches, in which he dismissed his earlier non-adaptive viewpoint: "My views have now completely changed, through appreciating the force of Gause's contention that two species with similar ecology cannot live in the same region ..." (Lack, 1947: 62). With his adoption of competition theory, Lack revised his interpretation of the Daphne and Hermanos populations:

Formerly I thought that the Daphne and Crossman forms might be of hybrid origin between $G$. fortis and $G$. fuliginosa. However, it would be highly remarkable if two species which occur together on many islands without interbreeding should, just in two places, give rise to a hybrid population. Further, it would be necessary to suppose that such interbreeding no longer takes place, since the Daphne and Crossman birds do not include any individuals in the upper range of size of $G$. fortis nor any in the lower range of size of $G$. fuliginosa. . . . Perhaps one of the two species became temporarily extinct there, or alternatively the islands may be too small to support populations of both species. If only one of the two species persisted, it might be expected to evolve a beak of intermediate type, since the foods normally taken by both species would be available for it. (Lack, 1947: 85).

All subsequent discussions of the Daphne and Hermanos intermediate phenotypes are based on this interpretation of Lack's. Bowman (1961) carried out a second major study of the Galápagos finches, and though he made no specific mention of these particular populations, Bowman made clear his general disapproval of Lack's (1947) emphasis on competition:

individuals of one species do not now 'compete' for food with certain other individuals of the same species . . . or with individuals of another sympatric species . . . and since there is no direct evidence that competition is occurring at the present time, I see no logical reason to assume that it must have occurred in the past. If . . closely related species of the Geospizinae have differentiated in geographic isolation, then ... owing to botanical differences between the islands... the birds would 
have evolved different feeding habits and habitat preferences ... when they were subsequently brought together in the same area, the different 'species' would select different niches in which to live ... Andrewartha and Birch (1954: 463) . . add that we are not obliged to suppose that dietary preferences and associated structural differences were developed as a result of 'competition'. (Bowman, 1961: $275)$.

Elsewhere, Bowman (1961: 272-273) stated:

I think it will be found that in all species of the Geospizinae, interisland differences in variability of bill size and shape as well as differences in the numbers of geospizine species present are directly correlated with interisland differences in density, diversity, and availability of the food resources.

Because Bowman did not explicitly discuss the Daphne or Hermanos populations, we must assume he would have applied the same reasoning to those situations. Thus he presumably would have said that these particular islands must have similar floral characteristics, different from surrounding islands, which would favour the evolution of an intermediate phenotype. At no point did Bowman propose a mechanism whereby colonists arriving with morphology appropriate to a particular island situation would be admitted to that community, while inappropriate colonists were denied entry (B. R. Grant \& P. R. Grant, 1982).

Though faulted on other counts (Selander, 1962; Bock, 1963), Bowman's study was important in that it added balance to Lack's (1947) advocacy of competition as being of singular importance in the evolution of Darwin's finches. Lack (1969) later acknowledged the validity of Bowman's (1961) main point, arguing that the ultimate answer must lie in some combination of interisland differences in both vegetation and in the complement of potential competitors. Although not often referred to in the textbooks, this rapprochement is evident in Lack's (1969: 259) final comprehensive statement on the Daphne and Hermanos populations:

it is almost certain that the forms on Daphne and Crossman are specialized derivatives of their respective species and not primitive relicts . . Whether the forms with intermediate beaks and presumed broader niches are specialized or primitive, they evidently persist on the small and outlying islands because they are more efficient there than the specialized forms on the large central islands, and not just because the latter have failed to reach the outlying islands. The frequency with which many of the finches wander from one island to another permits no other conclusion . . MacArthur and Levins (1967) . . . consider that the single generalized species will tend to be the more successful where the diversity of potential foods is smaller, the overall productivity is smaller, and the available resources are of unequal or variable abundance, while two more specialized species will tend to oust a single generalized one when these conditions are reversed. It may therefore be suggested that, for the species of Geospiza, the former type of conditions hold on small and outlying Galápagos islands, and the latter type on the large central islands.

Elsewhere, Lack (1969: 256) stated:

Summing up, the evidence... suggests that the beak differences between the island forms of each species are adapted to differences in the ecological conditions, in part to differences in the vegetation, and hence in the available foods, and in 
part to differences in the other species of Geospizinae present, which, through competition, affects the available foods.

P. R. Grant (1972) referred to the Daphne and Hermanos populations in his review of character displacement. He agreed with Lack (1969) that these small central populations are probably derived from neighbouring islands, where fuliginosa and fortis are sympatric, thus suggesting that their intermediacy is a derived product of allopatry and best termed character release. Grant went on to point out that it is difficult to explain how the morphological differences between species in sympatry evolved in the first place. Assuming an originally allopatric source for all species, currently sympatric species could either have diverged in allopatry due to habitat differences, and entered the same community as a result of selective colonization, or they may have been morphologically similar at contact, and have undergone subsequent character displacement (P. R. Grant, 1981a).

Harris (1973) reiterated Lack's (1969) changed explanation of the Daphne and Hermanos morphological intermediacy, adding that "These extremely interesting populations need further investigation, if indeed they are still extant, as the many individuals I have seen on Daphne were mostly assignable to G. fortis and G. fuliginosa" (Harris, 1973: 272).

Harris (1973) provides the most recent direct literature reference to the intermediate phenotypes on Daphne and Hermanos; subsequent authors, such as Williamson (1981: 209), have interpreted Harris's statement as implying that Daphne fortis are no longer intermediate in size. Abbott et al. (1977: 176) pursued Lack's (1969) move towards consensus, concluding that "Food supply and competition have jointly determined the ecological course of the radiation and resulting pattern of species diversity..." Strong, Szyska \& Simberloff (1979) criticized even this moderated application of competition theory, arguing that the distinctive Darwin's finch communities on different islands may largely be a product of random processes. Their conclusions have in turn been rebutted by P. R. Grant \& Abbott (1980), Hendrickson (1981) and Alatalo (1982), with the controversy by no means resolved (Simberloff \& Boecklen, 1981; Strong \& Simberloff, 1981). This ongoing debate underlines the topical need to review our interpretation of the morphological intermediacy of $G$. fortis on Isla Daphne Major.

\section{FOUR HYPOTHESES FOR THE DAPHNE PHENOTYPE}

The discussion above suggests several different explanations for the intermediacy of the Daphne phenotype, and although not emphasized here, presumably also for the Hermanos situation. As B. R. Grant \& P. R. Grant (1982) point out in a similar context, it is difficult to extract explicit, testable hypotheses verbatim from what have historically been general speculations about how Geospiza ecology or morphology evolved. At the risk of misconstruing earlier workers, we have reduced past explanations to four hypotheses. The first two hypotheses include founder effect/genetic drift and hybridization, which can loosely be described as "non-adaptive", and ascribed to Lack (1945). At that time Lack held that inter-island differences in finch morphology reflected the "Sewall Wright" or "Muller effects", although he suggested that hybridization 
may also have been relevant, particularly in the Daphne and Hermanos situations. The third and fourth hypotheses include adaptation to local food supplies and competitive release, and can be described as "adaptive". They can be traced to Bowman (1961) and Lack (1947) respectively, although Lack (1969) in fact came to advocate some combination of the two. We now turn to the modern data relevant to the Daphne situation, and then in the Discussion attempt to decide which hypothesis(es) are best supported by these data.

\section{METHODS}

Recent work on Daphne began in April 1973, when it was included in the eight sites surveyed by Abbott et al. (1977). A second brief study was conducted there in December 1973 (P. R. Grant et al., 1975; P. R. Grant et al., 1976; Smith et al., 1978). The present study began with a visit to Daphne in July 1975, coupled with surveys at Bahía Borrero on Isla Santa Cruz adjacent to Daphne and at Cerro Ballena on Isla Isabela adjacent to Los Hermanos (Fig. 2). A long term ecological study followed on Daphne, with visits before, during, and after the finch breeding season in 1976, 1977, and 1978. The majority of our data were collected in these three years, with occasional references to earlier sample periods and other sites, and some 1979 Daphne data provided by T. D. Price (unpublished).

Since 1973, similar methods have been used on different sites in the Galápagos, and in successive years at the same sites. These are described in detail in Boag (1981) and Boag \& Grant (1984) (see also P. R. Grant et al., 1975; Abbott et al., 1977; Smith et al., 1978; P. R. Grant \& B. R. Grant, 1980a). During each of the three annual visits to Daphne, normally in December-January prior to breeding, in the January-March breeding season, and concluding with a post-breeding visit in May-June, three types of data were collected. These included: (1) the number of seeds of each plant species in 50 $1 \mathrm{~m}^{2}$ quadrats randomly selected from three $50 \mathrm{~m} \times 100 \mathrm{~m}$ grids on the inner slope of the Daphne crater, the plateau south of the crater, and the south-facing outer slope of the island; (2) a standardized visual census of finches over the entire island; (3) 100 or more point records of food items eaten by ringed birds encountered during nonsystematic searches of the whole island.

Finches were continually caught in mist-nets, individually colour-ringed, and seven external morphological characters were measured. These included weight in $\mathrm{g}$ (WGT), and wing chord (WNG), bill length from the nares (BLG), bill depth at the nares (BDT), bill width at the base of the mandible (BWD), and bill length at a depth of $4 \mathrm{~mm}$ (LA4, a bill 'pointedness' measure), all in $\mathrm{mm}$ (see Boag, 1983). Continuous records were kept of ringed birds known alive or found dead. Each year during the breeding season we ringed nestlings and compiled nest histories. All these data were reduced to groups of records for each study period, summarizing temporal changes in variables such as finch numbers, plant cover, seed abundance, seed diversity, feeding behaviour, rainfall, etc. The data and correlation matrices for 47 of the variables measured over these study periods are given in Boag (1981). Complete sets of comparable data are available for the nine periods resulting from our visits in 1976, 1977, and 1978; parts of the data for July 1975 and April and December 1973 are also included where possible, but in some cases the data were collected using different methods (see Boag \& Grant, 1984). 


\section{RESULTS}

\section{Morphology}

Our measurement data confirm Lack's $(1945,1947)$ finding that the Daphne population is morphologically intermediate to G. fuliginosa and G. fortis found elsewhere, thus refuting Harris's (1973) and Williamson's (1981) suggestion that the unusual Daphne population no longer exists. Photographs of Daphne Geospiza beaks are given in Fig. 3. In Fig. 3A, note the steeply curved culmen on the larger male to the left, as well as the deep base to its lower bill. The smaller male has a straighter culmen and shallower mandible base, giving the beak a more pointed cross-section. Figure 3B contrasts the beaks of a typical Daphne fortis female and a female fuliginosa measured on Daphne.

In Fig. 4 our measurement data are presented in a form similar to that of Lack (1947) (Fig. 1). The upper histograms in Fig. 4A show bill depth frequency distributions for 182 G. fuliginosa (BBFG) and G. fortis (BBFT) measured in July 1975 at Bahía Borrero, $8 \mathrm{~km}$ upwind from Daphne on Isla Santa Cruz (Fig. 2). The middle histogram displays the bill depth distributions for all Daphne birds belonging to either fortis (DPFT) or fuliginosa (DPFG) and alive on Daphne in May-June 1976. The bottom histogram in Fig. 4A displays the bill depths of those 1976 individuals still present on Daphne in 1978. Figure 4B is identical to Fig. 4A except that it shows canonical variate (discriminant function) scores instead of bill depth measurements (program BMDP7M was used, see Dixon \& Brown, 1979).

The discriminant analysis generated an axis of maximal separation between the two Bahía Borrero populations, the putative ancestral populations of the Daphne fortis. This axis was used to array the Daphne birds according to their similarity to the potential founder populations. Such a technique is used to provide a multivariate summary of situations in which introgression may be occurring (Rohwer, 1972; Schueler \& Rising, 1976; Albrecht, 1980). The function separating the BBFG and BBFT populations was highly significant $\left(F_{7,174}=260.09, P<0.001\right)$, with coefficients weighting bill width $(0.86)$, bill LA4 $(-0.58)$, bill depth $(0.53)$, and bill length $(0.44)$ heavily. The total Mahalanobis $D^{2}$ between BBFG and BBFT centroids was 6.44, with DPFT 1.85 units from BBFT and 4.59 units from the BBFG centroid. Thus whether a single character is used, or a multivariate summary character, the Daphne birds are definitely intermediate to fuliginosa and fortis populations elsewhere, with a tendency to resemble fortis more closely on average, and in 1976, a moderate skew towards fuliginosa.

A question which often arises in discussions of Darwin's finch morphometrics is whether it is really possible to reliably assign individuals to species. The Geospiza, particularly variable species such as $G$. fortis, are difficult to identify using only visual observations of unmarked individuals. However, our identifications, based on colour-ringed birds that have been handled and measured, appear quite accurate. In Table 1 we show the results of a second, three-group discriminant analysis, in which a variety of Daphne birds were classified according to their multivariate affinities to BBFG, BBFT, and DPFT. Only about $2 \%$ of the Daphne birds we had originally called fortis actually appear closer to BBFG. G. fortis at Bahía Toruga (BTFT) and Cerro Colorado (CCFT) on Isla Santa Cruz (Fig. 2) are generally larger than BBFT and DPFT, 

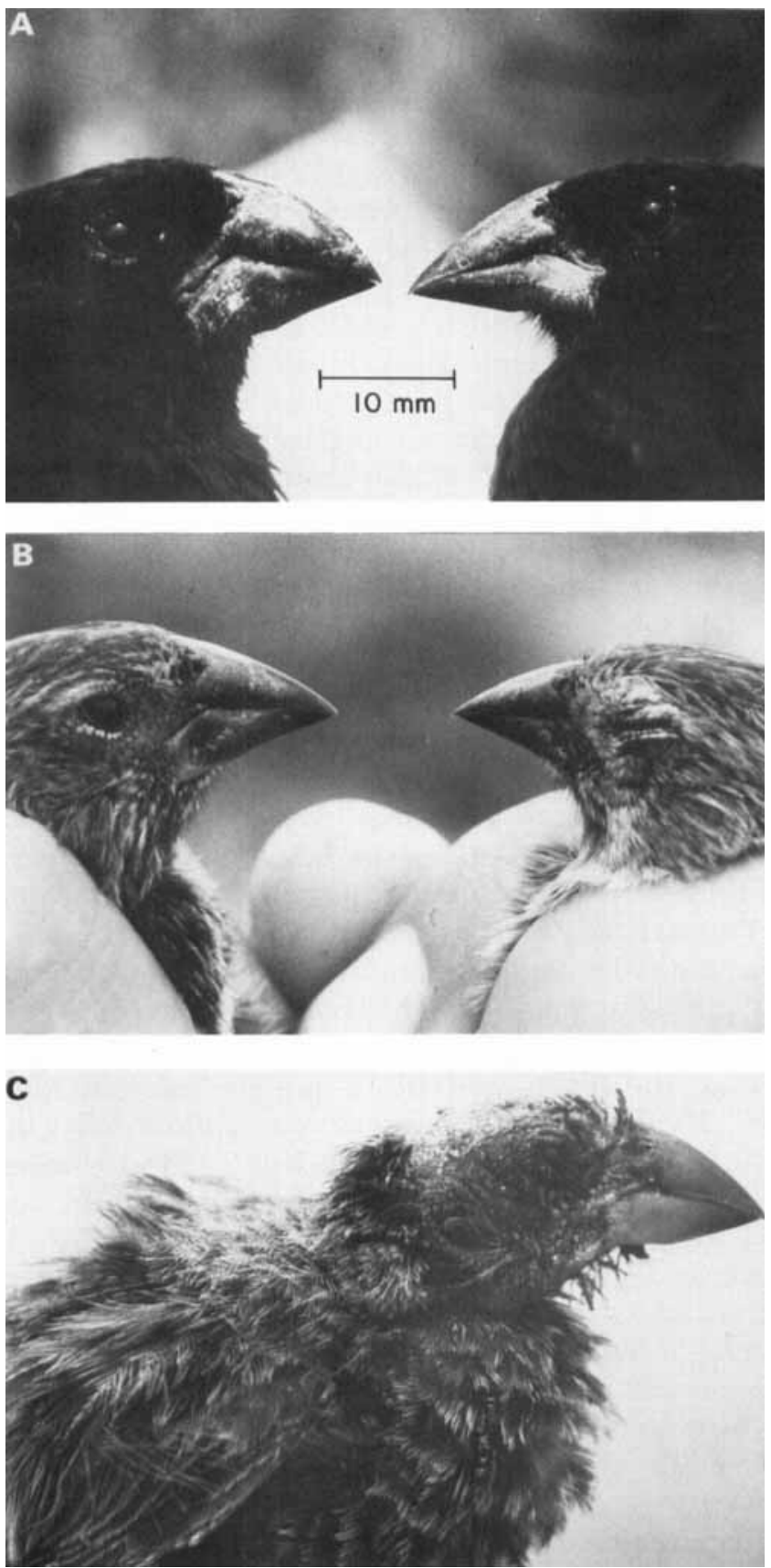

Figure 3. Photographs of Daphne Geospiza. A, Variation in beak size and shape in two blackplumaged, male Daphne G. fortis. Both display the black bills of males in breeding condition. B, Daphne fortis female on the left, Daphne fuliginosa female on the right. Both have brown bills typical of breeding females. C, Daphne fortis female No. 356, found dying in May 1977. Note bald head, worn plumage and light bill indicating non-breeding condition. 

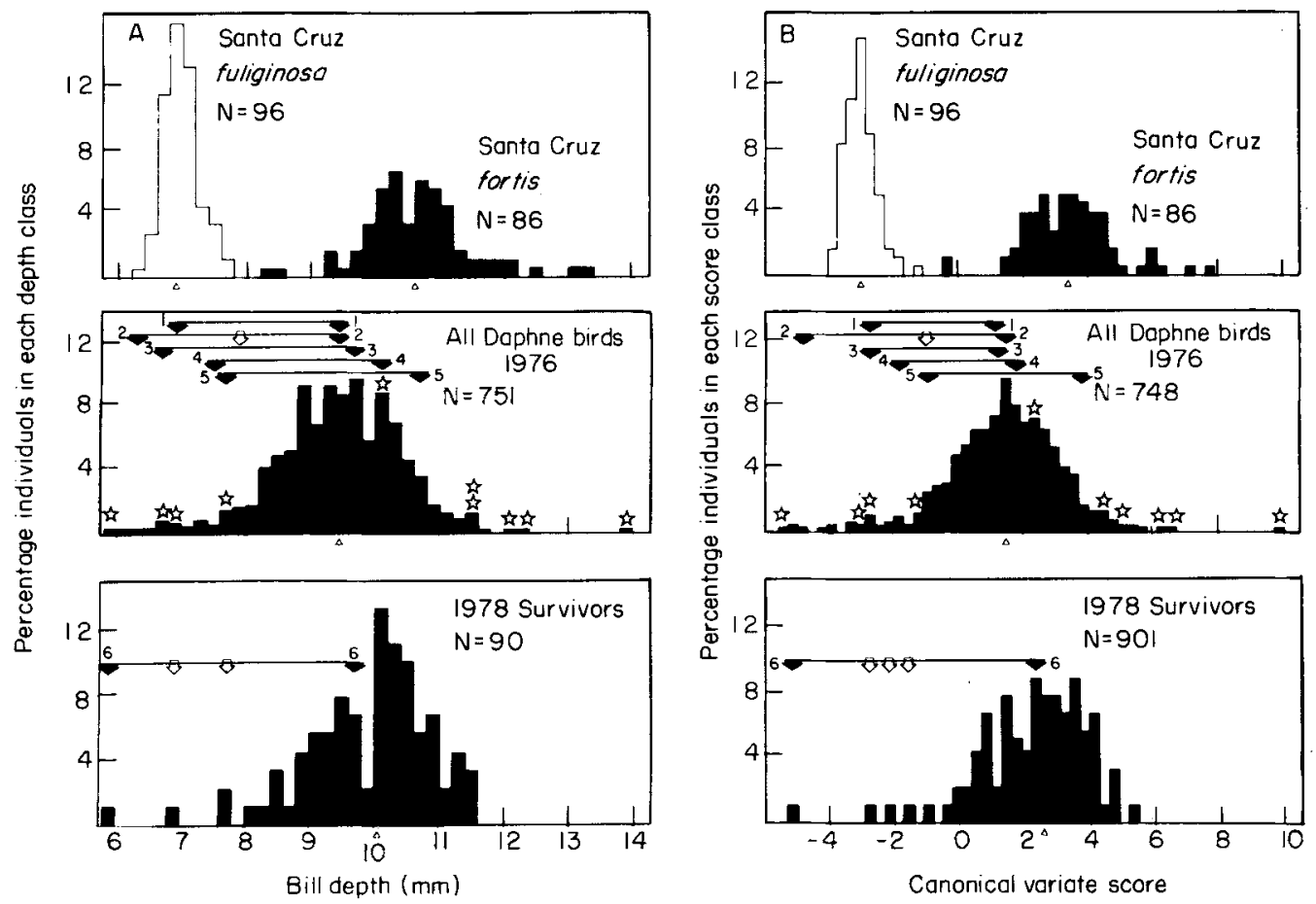

Figure 4. A, Frequency distributions of bill depth at Bahía Borrero, Isla Santa Cruz and Isla Daphne Major in 1976 and 1978. Small triangles below the horizontal axes indicate group means. The horizontal lines with terminal arrows represent matings between fortis and fuliginosa; the open arrows are hybrid offspring produced by those matings (in 1978 the right arrow represents two offspring). The stars indicate 10 birds known to immigrate to Daphne from Santa Cruz in May 1977. B, Identical to A, but canonical variate scores are shown (see text).

and none were misclassified to BBFG. The smaller fortis at Cerro Ballena on Isla Isabela, opposite the Hermanos, had more 'fuliginosa-like' individuals. $G$. fuliginosa were most accurately identified, as they are less variable. Even the fuliginosa on Isla Tortuga, off Isabela like the Hermanos, and also containing some large individuals, had close affinities to BBFG. Misclassification of DPFG appeared higher, with up to $19 \%$ of the 31 DPFG being closer to DPFT. This reflects the increased variability of this population, discussed later (Table 9). But only one of the six misclassified DPFG was actually a significant distance from the DPFG centroid $(P=0.04)$. Furthermore, many of the misclassified DPFG, DPFT, and BBFT had been recognized as problem cases in our original field notes, having been labeled "fuli-fortis".

\section{Immigration}

Figure 4 shows 10 stars, each representing a known Geospiza immigrant to Daphne. These 10 birds were identified as immigrants when a mixed flock of juvenile fortis, fuliginosa and small tree finches (Camarhyncus paroulus) were netted on Daphne in May 1977. They had slightly different plumage compared to Daphne finches, and behaved differently than residents (Boag, 1981). Furthermore, they were juveniles in a year in which no fuliginosa or fortis had 
Table 1. A. posteriori classification of Geospiza based on a three group (BBFG, BBFT, DPFT) discriminant analysis. Shown are the percentages of various groups of finches classified into the three groups actually analysed

\begin{tabular}{lrrrr}
\hline $\begin{array}{l}\text { Original } \\
\text { groups }\end{array}$ & \multicolumn{2}{c}{ Classification categories } & DPFT \\
\hline BBFG & \multicolumn{1}{c}{ BBFG } & BBFT & 0.0 \\
BBFT & 96 & 100.0 & 0.0 & 12.8 \\
DPFT & 86 & 1.2 & 86.0 & 88.6 \\
DPFG & 699 & 2.4 & 9.0 & 16.0 \\
IMMG & 25 & 84.0 & 0.0 & 10.0 \\
HYFT & 10 & 40.0 & 50.0 & 25.0 \\
HYFG & 4 & 0.0 & 75.0 & 33.3 \\
HYOF & 6 & 66.7 & 0.0 & 25.0 \\
CCFG & 4 & 75.0 & 0.0 & 0.0 \\
CCFT & 25 & 100.0 & 0.0 & 43.4 \\
BTFG & 106 & 0.0 & 56.6 & 3.6 \\
BIFT & 28 & 96.4 & 0.0 & 20.2 \\
CBFG & 84 & 0.0 & 79.8 & 0.0 \\
CBFT & 78 & 100.0 & 0.0 & 22.6 \\
IOFG & 53 & 5.7 & 71.7 & 0.0 \\
\hline
\end{tabular}

Separation of the three groups analysed was highly significant $\left(F_{14,1744}=129.83, P<0.001\right)$, with coefficients of the first canonical variate $\left(R^{2}=74.2 \%\right)$ emphasizing bill width $(-1.39)$ and bill LA4 $(-0.46)$, and of the second $\left(R^{2}=25.8 \%\right)$, bill length $(-1.47)$ and weight $(0.80)$. IMMG are known immigrants, HYFT are fortis mated to fuliginosa, HYFG are fuliginosa mated to fortis, and HYOF are hybrid offspring. CCFG, CCFT, BTFG, BTFT, CBFG, and CBF'T are fuliginosa and fortis from Cerro Colorado and Bahía Tortuga on Isla Santa Cruz and from Cerro Ballena on Isla Isabela, respectively. TOFG are fuliginosa from Isla Tortuga, near Cerro Ballena and the Hermanos (Fig. 2).

bred on Daphne. Except for a single individual in the center of the Daphne morphological distributions, the immigrants are atypical of Daphne birds. In the three group discriminant analysis (Table 1), four small immigrants were confidently assigned to BBFG, five large immigrants to BBFT, and only a single intermediate immigrant was assigned to DPFT, although it was not significantly different from the BBFT centroid.

Lack (1945, 1947) noted fuliginosa on Daphne, but felt they were too uncommon to be residents. Harris (1973) saw fuliginosa on Daphne, and P. R. Grant et al. (1975) recorded small numbers of fuliginosa, large ground finches (G. magnirostris), yellow warblers (Dendroica petechia), one warbler finch (Certhidea olivacea), and one flycatcher (Myiarchus magnirostris), none of which are residents (Harris, 1974). During our study (Boag \& Grant, 1984), fuliginosa and magnirostris were consistently present on Daphne $(0.5-5 \%$ of the total Geospiza population). We also noted a single male Certhidea on Daphne from January 1976 until mid-1977, several small tree finches, a single large tree finch (C. psittacula) in 1978, and a single vegetarian finch (Camarhyncus crassirostris) in May 1976. Yellow warblers were regularly present, with one pair nesting unsuccessfully in 1976, and in May 1976 a single blackpoll warbler (Dendroicha striata) was netted (Boag \& Ratcliffe, 1979). A woodpecker finch (Camarhyncus pallidus) was recorded by S. V. Venables in January 1939 and in February 1981 T. D. Price saw a cuckoo (Coccyzus melacoryphus) on the island (Price \& Millington, 1982).

Most finch immigrants on Daphne have been under one year of age upon arrival. Few immigrants were either ringed as adults or remained long enough 
to mature, but a small sample of songs of male fuliginosa and magnirostris recorded on Daphne by Ratcliffe (1981) were sonographically similar to songs of the same species recorded on Santa Cruz. All these data suggest that immigration of Geospiza and other landbirds to Daphne is not uncommon, and that most immigrants are dispersing juveniles from Isla Santa Cruz.

\section{Hybridization}

Given that $G$. fuliginosa immigrate to Daphne, and form a small but persistent population there, is there evidence for mixed fortis-fuliginosa matings? The answer is yes. In 1976 between 1.1 and 2.7\% of Daphne fortis breeding pairs were actually fortis-fuliginosa pairs, while in 1978 between 2.4 and $3.5 \%$ of the breeding pairs were mixed (Boag, 1981). Although no fortis bred in 1977 due to the lack of rainfall (Boag \& Grant, 1984), two fortis-fuliginosa pairs were identified that year based on behavioural observations. The six bestdocumented pairs are illustrated in Fig. 4, where horizontal lines connect solid arrows indicating the members of each pair. Of 13 known hybrid offspring produced during the Daphne study, four were recaptured and measured, and their measurements are indicated by open arrows in Fig. 4. The two fuliginosa females (Nos 6 and 265) producing these four offspring were rather small; thus their offspring are also small, although they clearly display the morphological intermediacy predicted by the high heritabilities for morphology in the Geospiza (Boag \& Grant, 1978). Table 1 shows that in a three-group discriminant analysis, three of the hybrids (HYOF) were closest to BBFG and one to DPFT. The Daphne fortis mated to fuliginosa (HYFT) were not unusually small, all being classified as BBFT or DPFT. The classification of fuliginosa involved in interspecific matings (HYFG) was more uncertain; Table 1 suggests that up to one-third of those birds were closer to DPFT than BBFG, although the two misclassified fuliginosa were in fact not significantly different from the BBFG centroid. The two fuliginosa females identified above as the parents of hybrid offspring were definitely fuliginosa, being classified as BBFG in Table 1 , and both significantly smaller than the DPFT centroid $(P<0.001$ and $P=0.009)$.

As part of a separate study of species recognition in the Geospiza, Ratcliffe (1981) conducted mount presentation and song playback experiments with Daphne fortis. Daphne fortis distinguished between mounts or songs of Daphne fortis and those of Daphne scandens, but did not distinguish between mounts from their own population and those of Santa Cruz fuliginosa. In contrast, when Santa Cruz fortis and fuliginosa were tested in sympatry, both displayed a high degree of response selectivity, consistently preferring mounts or songs of their own species (Ratcliffe, 1981; Ratcliffe \& Grant, 1983a, b). These results provide a proximate reason for the regular hybridization between Daphne fortis and fuliginosa. The fact that sex ratios on Daphne may sometimes favour males (Boag \& Grant, 1981), may increase the likelihood of mate choice mistakes, if female choice depends on the relative abundances of mate types available (Ficken \& Ficken, 1968; Gill \& Murray, 1972). Even in full sympatry, occasional hybridization may still occur because of "misimprinting" accidents (Bowman, 1983). Ratcliffe (1981) describes Daphne fortis and scandens individuals singing the song of the opposite species, apparently because they were reared in the wrong species' nest or underwent interspecific fostering after fledging. This 
apparently labile learning mechanism might produce individuals with an increased likelihood of interspecific matings (Cheke, 1969; Bowman, 1983).

It is not yet possible to establish whether hybridization is selected against on Daphne. In years such as 1978 when there was an excess of males, unmated males have the opportunity to increase their genetic contribution from zero to some finite value by mating with a fuliginosa, the value depending on the future success of hybrid offspring. No known hybrids have been observed to breed on Daphne, although some of the 1978 hybrids reached maturity in 1979. Also in that year, the 1978 fuliginosa-fortis pair shown in Fig. 4 bred successfully again (T. D. Price, pers. comm.). Hybrid offspring display morphology intermediate to that of their parents, suggesting that if mating remained random, subsequent backcrosses would produce progressively more 'fortis-like' offspring (Fig. 4) (Boag, 1983). To assess the likelihood of additional hybrids in the 1976 population, the data shown in Fig. 4 were subjected to another discriminant analysis, this time including BBFG, BBFT, DPFT and a fourth group consisting only of the four known hybrid offspring (HYOF). With such a small fourth group the results must be accepted with caution, but based on the assumption of equal prior probabilities for each group, the a posteriori classification suggested that the 703 DPFT would be allocated as follows: $0.7 \% \mathrm{BBFG}, 9.2 \% \mathrm{BBFT}$, $83.8 \%$ DPFT, and $6.3 \%$ HYOF. The same analysis allocated over $10 \%$ of the BBFG to HYOF and up to $60 \%$ of the 31 DPFG to HYOF. Thus up to $8.6 \%$ of the combined DPFG and DPFT population could have been $F_{1}$ hybrids in 1976.

\section{Population sizes and food supplies}

Between May 1976 and March 1978, the Daphne fortis population decreased by $85 \%$ and the scandens populations by $66 \%$ (Fig. 5A) (Boag \& Grant, 1984). Over the 10 sample periods in Fig. 5A, the coefficient of variation (CV) for fortis population size was $65.4 \%$, while that of scandens was $30.9 \%$, a significant difference (ratio of squared CVs, $F=4.47, P<0.025$ ). Simultaneously, by 1978 the sex ratio in both species had become skewed in favour of males, by up to $5 \delta \hat{\jmath}: 19$ (Boag \& Grant, 1984).

The drop in population size was correlated with reduced seed availability. Using the nine sample periods from January 1976 to June 1978, the correlations between total edible seed abundance and finch numbers were $r=0.86(\mathcal{N}=9$, $P=0.003)$ for fortis and $r=0.78(\mathcal{N}=9, P=0.014)$ for scandens (see Boag $\&$ Grant, 1981: fig. 1). The reduction in seed abundance was associated with a failure of plant production in 1977, a result of drought conditions that year (Boag \& Grant, 1981; 1984). Rainfall estimates for the intervals prior to successive sample periods were strongly correlated with estimates of total plant cover in those sample periods $(r=0.86, \mathcal{N}=10, P<0.001)$, providing the link between rainfall, plant growth, and eventual seed production. Boag \& Grant (1984) discuss how "wet season" insect production was similarly affected by the rainfall regime.

As the seed abundance dropped on Daphne, the types of seeds available changed from a diverse array of fairly small, soft seeds to a less diverse, and much harder set of seeds. Small seeds such as Chamaesyce spp., Sida salviifolia, Portulaca howelli, and Amaranthus schlerantoides became very scarce by the end of 

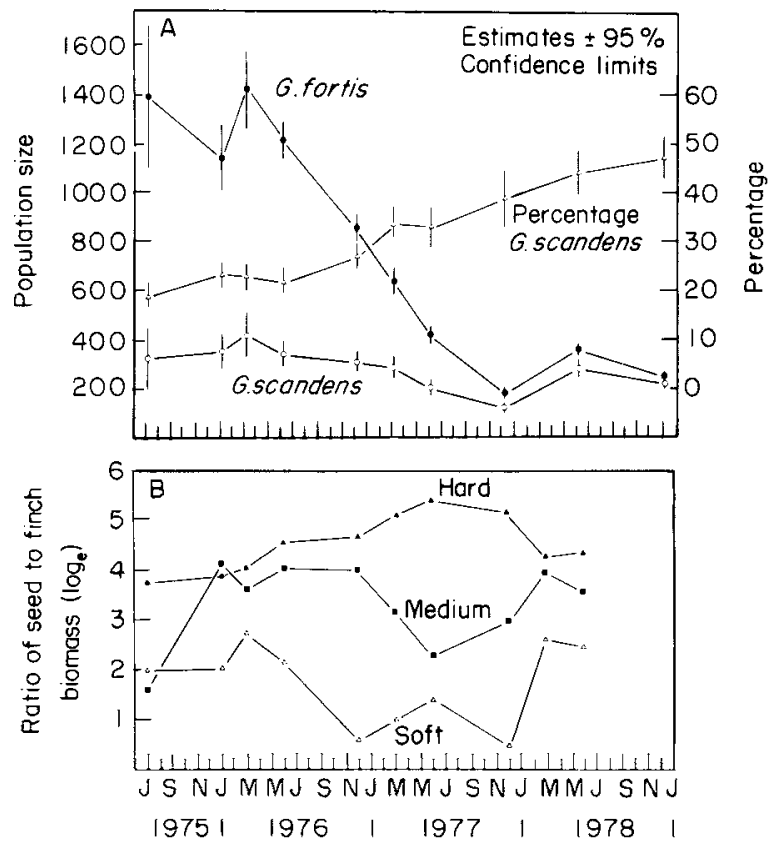

Figure 5. A, Chronological changes in G. fortis and G. scandens population sizes on Daphne, and the change in the proportion of scandens relative to the combined numbers of fortis and scandens. All points are means $\pm 95 \%$ confidence limits. $B$, Changes in the ratio of seed biomass in three $\sqrt{\mathrm{DH}}$ classes (soft, medium, hard) to the combined biomass of the fortis and scandens on Daphne. Scaled to $\log _{e}$.

1977, while large, hard seeds, particularly Tribulus cistoides, became relatively more abundant.

We use the $\sqrt{\mathrm{DH}}$ index created by Abbott et al. (1977) as a composite measure of seed size and hardness, where D is a seed's depth $(\mathrm{mm})$ and $\mathbf{H}$ its loudness (kgf). Table 2 shows how the average $\sqrt{\mathrm{DH}}$ on Daphne changed over the course of the study (see Boag \& Grant, 1981: fig. 1.) $\sqrt{\mathrm{DH}}$ values are higher at the end of the dry season, and then decrease in the wet season as small seeds are produced in large amounts (especially by annuals). $\sqrt{\mathrm{DH}}$ values remained high throughout 1977, indicating that the Daphne seed environment had become dominated by large hard seeds.

Figure $5 \mathrm{~B}$ illustrates this in another way, showing the changing ratio between the estimated edible seed standing crop on Daphne (in $\mathrm{kg}$ ) and the combined biomass (in $\mathrm{kg}$ ) of fortis and scandens. Seed abundances in each sample period were extrapolated to entire island standing crops by multiplying seed densities in three seed size classes on each of three study grids by the total area of that habitat type on Daphne. The seed types include soft seeds $(\sqrt{\mathrm{DH}}<1.0$, e.g. Chamaesyce, Sida, Portulaca, Amaranthus), medium seeds $(\sqrt{\mathrm{DH}} \geqslant 1.0$ but $<4.0$, e.g. Cenchrus, Opuntia, Croton) and hard seeds $(\sqrt{\mathrm{DH}} \geqslant 4.0$, e.g. Tribulus, Bursera). While the amounts of soft and medium seed available per finch dropped in 1977, the availability of hard seeds per finch actually increased. Other types of 'soft' foods showed a similar pattern of disappearance; for instance, the average number of flowers (from which finches take nectar, pollen, and insects) of all species per $\mathrm{m}^{2}$ was strongly correlated with the weight of soft seeds per $\mathrm{m}^{2}$ 
Table 2. Characteristics of seed available at various Galápagos sites

\begin{tabular}{llccccc}
\hline \multicolumn{2}{c}{ Sample } & Seed & $\begin{array}{c}\sqrt{\mathrm{DH}} \text { using } \\
\text { Seed } \\
\text { numbers }\end{array}$ & $\begin{array}{c}\sqrt{\mathrm{DH}} \text { using } \\
\text { Seed } \\
\text { volume }\end{array}$ & $\begin{array}{c}\text { Seed } \\
\sqrt{\mathrm{DH}} \\
\text { diversity }\end{array}$ & $\begin{array}{c}\text { Seed } \\
\text { abundance }\end{array}$ \\
\hline Daphne & Apr. 1973 & 18 & 0.84 & 5.66 & 3.85 & 4.27 \\
& Dec. 1973 & 14 & 1.19 & 3.49 & 1.75 & 12.71 \\
& Jul. 1975 & 20 & 1.01 & 6.25 & 3.09 & 2.39 \\
& Mar. 1976 & 20 & 1.03 & 4.62 & 3.84 & 8.72 \\
& Jun. 1977 & 16 & 6.53 & 6.70 & 2.53 & 2.23 \\
Borrero & Dec. 1977 & 11 & 5.19 & 8.25 & 2.74 & 1.65 \\
& Apr. 1973 & 20 & 1.75 & 2.51 & 3.22 & 0.65 \\
& Dec. 1973 & 10 & 3.39 & 3.52 & 1.99 & 0.06 \\
Ballena & Jul. 1975 & 20 & 1.48 & 1.67 & 3.31 & 4.86 \\
Hermanos. 1975 & 19 & 0.73 & 2.91 & 1.70 & 4.09 \\
\hline
\end{tabular}

Seed species include only those encountered in the quadrats. $\sqrt{\mathrm{DH}}$ indices were calculated as described in the text, using numbers of seeds $/ \mathrm{m}^{2}$ and seed volume in $\mathrm{cm}^{3} / \mathrm{m}^{2}$. Seed $\sqrt{\mathrm{DH}}$ diversity is $1 / \Sigma p_{i}^{2}$. Seed abundances are $\mathrm{cm}^{3} / \mathrm{m}^{2}$. The number of species and $\sqrt{\mathrm{DH}}$ diversity columns include Merremia and lpomoea, but they have been omitted from other measures. Our Daphne samples use data from the inner slope and plateau study areas only, as sampled by Abbott et al. (1977). See also Boag \& Grant (1984).

$(r=0.86, \mathcal{N}=10, P<0.001)$, but not with the weight of hard seeds per $\mathrm{m}^{2}$ $(r=0.19, \mathcal{N}=10, P=0.60)$.

As seed abundance dropped, and average seed size increased, the diversity of seeds and other foods dropped (Table 2). Thus in March 1976, 21 species of living plants were recorded one or more times in the 50 Daphne vegetation quadrats, as were 20 seed species. In June 1977, these numbers had dropped to 10 and 16 respectively. From the point of view of the finches, one particularly important aspect of diversity is the distribution of seed biomass across successive $\sqrt{\mathrm{DH}}$ classes. Using relative abundances based on seed biomass and the diversity index $1 / \Sigma p_{i}^{2}$ (Rotenberry, 1980), diversity across nine $\sqrt{\mathrm{DH}}$ categories was positively correlated with the amount of rain falling in the interval between each sample period $(r=0.81, \mathcal{N}=10, P=0.004)$.

\section{Islands and their seeds: is Daphne unusual?}

It is difficult to compare the foods available to finches on different islands, because sites may not have experienced identical recent climatic conditions or have been sampled simultaneously using identical methods. We have attempted to summarize the available data in Fig. 6, which shows plots of total seed abundance accumulated across successive categories of increasing $\sqrt{\mathrm{DH}}$. A rapidly rising convex curve indicates an abundance of small, soft seeds, while a concave curve asymptoting at high $\sqrt{\mathrm{DH}}$ values suggests a preponderance of hard seeds, and a relatively straight line suggests an even distribution of seed abundance across $\sqrt{\mathrm{DH}}$ categories. A corresponding series of average $\sqrt{\mathrm{DH}}$ values, as well as estimates of the number of seed species, seed abundance, and diversity across $\sqrt{\mathrm{DH}}$ categories are shown in Table 2.

Figure 6A contrasts the wet and dry season results recorded by Smith et al. (1978) on Daphne and at Bahía Borrero, on adjacent Isla Santa Cruz. In 1973, 

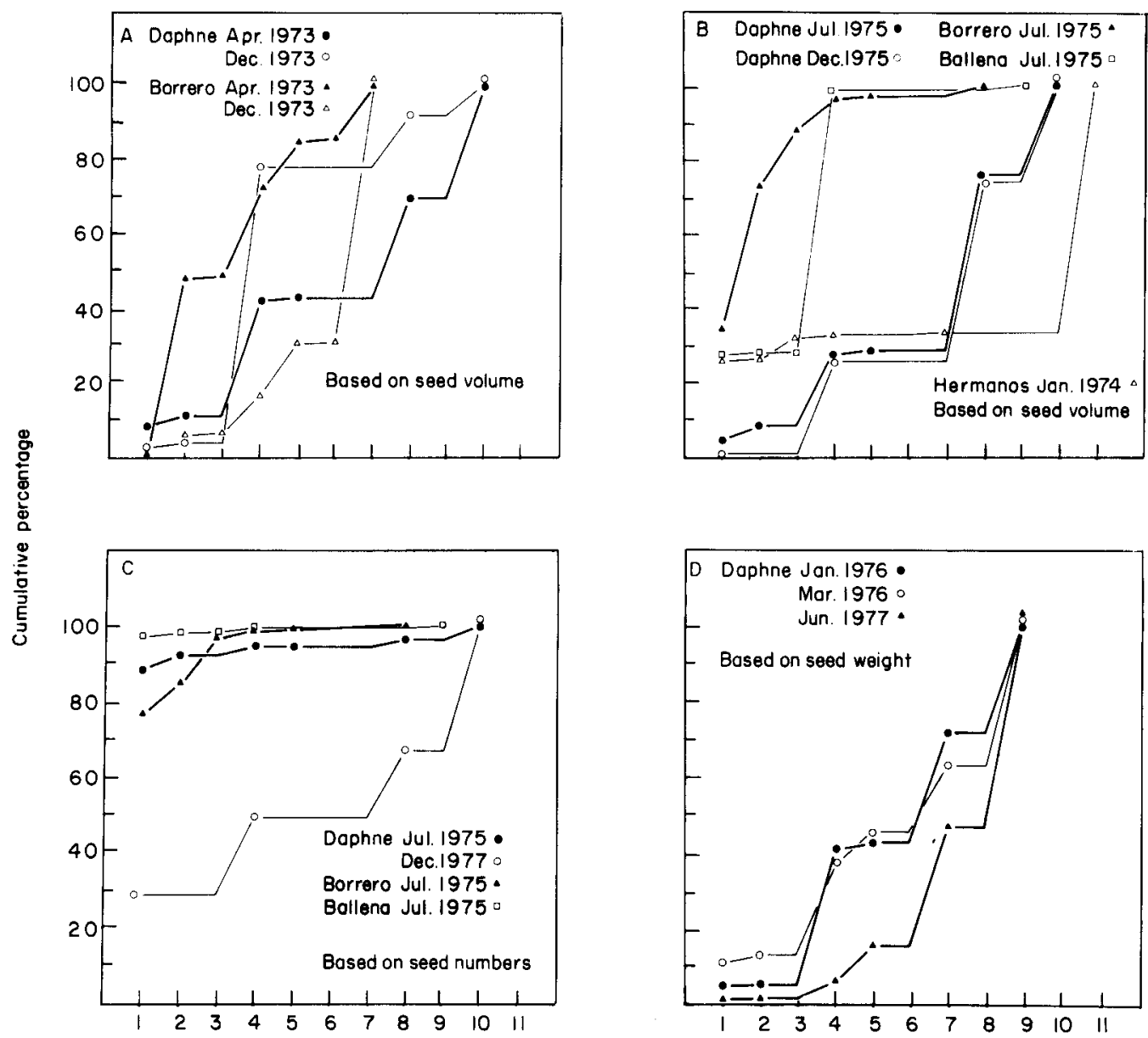

$\sqrt{D H}$ closs

Figure 6. Cumulative percentages of seed abundance in successive $\sqrt{\mathrm{DH}}$ index classes. A, Results based on seed volume for Daphne Major in April 1973 and December 1973. Also given are similar results for Bahía Borrero, on Isla Santa Cruz. B, Data similar to A, but for different years and additional sites. Cerro Ballena is on Isla Isabela, adjacent to the Hermanos. C, Data similar to B, but using seed numbers instead of volume. All sites except Daphne in 1977 become difficult to distinguish 'soft seed sites'. D, Plots comparable to B and C but based on seed weight and using revised sampling procedure begun in 1976.

Bahía Borrero had a dry season seed environment consisting of larger and harder seeds (Table 2, average $\sqrt{\mathrm{DH}}=3.52$ ) compared to the wet season ( $\sqrt{\mathrm{DH}}=2.51$ ) while on Daphne the opposite was true. A closer examination of the original data showed that the average $\sqrt{\mathrm{DH}}$ on Daphne in December 1973 was influenced primarily by a high abundance of Opuntia echios seeds, most in unripe fruits on cacti and not available to the finches.

Figure 6B shows similar data collected by us in July 1975 on Daphne, Bahía Borrero, and Cerro Ballena, on Isla Isabela adjacent to the Hermanos (Fig. 2). At this time of year, shortly after a fairly wet 'wet season', Bahía Borrero had an extremely soft seed environment $(\sqrt{\mathrm{DH}}=1.67)$, while Daphne had, if anything, a harder seed environment than in April $1973(\sqrt{\mathrm{DH}}=6.25)$. Cerro Ballena displayed characteristics intermediate to those at Borrero and Daphne, 
having many small seeds, even more medium seeds, and virtually no hard seeds. Figure 6B includes a plot for Hermanos III, based on a small sample of quadrats collected in January 1974. Soft seeds were present in an amount similar to Ballena in 1975, but there were no medium seeds, and a lot of hard seeds, like Borrero in December 1973 or Daphne in 1975 and 1977. As on Daphne, the steep rise in the Hermanos seed volume at the hard end of the seed spectrum was largely due to Tribulus cistoides.

When seed numbers are used to estimate the cumulative abundance of seeds across $\sqrt{\mathrm{DH}}$ categories (Fig. 6C), as used by Abbott et al. (1977), the curves differ from Fig. 6B. Although a soft seed site by both abundance measures, Bahia Borrero was the softest seed site based on volume, but when seed numbers are used, it ranks third after Daphne and Ballena in 1975 (Table 2). Ballena, the other large island site, had over $95 \%$ of its seeds with a $\sqrt{ } \mathrm{DH}<1.0$ when seed numbers were used. Finally, Fig. 6D shows curves for Daphne based on our present sampling procedure, which includes the outer island grid and uses seed biomass to estimate abundance. It suggests, as does Fig. 6C, that the Daphne seed environment changes from a wet season or wet year seed array rather evenly distributed across $\sqrt{\mathrm{DH}}$ categories, to a dry season or dry year array of larger, harder seeds. Comparing Hermanos to Cerro Ballena, and Daphne to Bahia Borrero, the distinctive feature of the small islands appears to be the possibility of large, recurrent declines in the abundance of small seeds, leaving relatively few alternative dry season foods beside seeds such as Tribulus. Larger islands appear to have larger amounts of small seed, and probably have a wider variety of alternative dry season feeds, especially if finches use the option of dry season movements to other habitats.

Table 3. Upper triangular matrix measures similarity of seed species composition among central Galápagos sites, while the lower matrix describes similarity of distributions of seed volume across $\sqrt{\mathrm{DH}}$ categories among sites

\begin{tabular}{|c|c|c|c|c|c|c|c|c|c|c|}
\hline & \multicolumn{5}{|c|}{ Daphne } & \multicolumn{3}{|c|}{ Borrero } & \multirow{2}{*}{$\frac{\text { Ballena }}{\text { Jul. }}$} & \multirow{2}{*}{$\frac{\text { Hermanos }}{\text { Jan. }}$} \\
\hline & Apr. & Dec. & Jul. & Jun. & Dec. & Apr. & Dec. & Jul. & & \\
\hline \multicolumn{11}{|l|}{ Daphne } \\
\hline Apr. 1973 & & 0.84 & 0.92 & 0.88 & 0.69 & 0.41 & 0.21 & 0.37 & 0.38 & 0.56 \\
\hline Dec, 1973 & 0.56 & & 0.81 & 0.63 & 0.75 & 0.29 & 0.17 & 0.18 & 0.31 & 0.67 \\
\hline Jul. 1975 & 0.79 & 0.46 & & 0.86 & 0.73 & 0.35 & 0.14 & 0.31 & 0.42 & 0.55 \\
\hline Jun. 1977 & 0.71 & 0.48 & 0.87 & & 0.81 & 0.32 & 0.46 & 0.33 & 0.34 & 0.60 \\
\hline Dec. 1977 & 0.78 & 0.48 & 0.92 & 0.90 & & 0.12 & 0.29 & 0.19 & 0.33 & 0.48 \\
\hline \multicolumn{11}{|l|}{ Borrero } \\
\hline Apr. 1973 & 0.30 & 0.27 & 0.25 & 0.26 & 0.24 & & 0.65 & 0.73 & 0.35 & 0.34 \\
\hline Dec. 1973 & 0.15 & 0.12 & 0.14 & 0.12 & 0.11 & 0.44 & & \multirow{2}{*}{0.60} & 0.73 & 0.33 \\
\hline Jul. 1975 & 0.23 & 0.15 & 0.20 & 0.14 & 0.11 & 0.50 & 0.15 & & 0.36 & 0.34 \\
\hline $\begin{array}{l}\text { Ballena } \\
\text { Jul. } 1975\end{array}$ & 0.39 & 0.75 & 0.25 & 0.26 & 0.26 & 0.26 & 0.11 & 0.36 & & 0.18 \\
\hline Hermanos & & & & & & & & & & \\
\hline Jan. 1974 & 0.40 & 0.11 & 0.31 & 0.21 & 0.27 & 0.05 & 0.02 & 0.33 & 0.28 & \\
\hline
\end{tabular}

Species composition similarities are $S=2 C /(A+B)$, where $A$ and $B$ are the total number of species on two sites and $C$ is the number of species common to both sites (Odum, 1971). Similarity among sites of the distribution of seed volume across $\sqrt{\mathrm{DH}}$ categories is $S=\Sigma$ min. $\left(p_{1 i}, p_{2 i}\right)$ (Whittaker, 1960). Ipomoea and Merremia were excluded from both analyses. 
Daphne appears to have roughly the same numbers of seed species available in the same to higher quantities as other sites (Table 2). Table 3 shows that the average seed species composition similarity (SCS) was highest among sample periods on Daphne (0.81) and at Borrero (0.66). SCS was lowest between Cerro Ballena and Hermanos (0.18), and between Daphne and Borrero $(0.30)$ averaged across 1973 and 1975. Ballena and Hermanos were more similar to Daphne than they were to Borrero. Seed $\sqrt{\mathrm{DH}}$ similarity (SDS) showed a similar pattern insofar as the highest SDS values were among sample periods on Daphne $(0.70)$ and at Borrero $(0.36)$, while the average SDS between Daphne and Borrero was low (0.21). The Hermanos SDS was again more like that of Daphne than Borrero, but unlike SCS it realized its highest value with Ballena. Overall, the Daphne seed community has a diversity and abundance like that seen at nearby arid zone sites, but is somewhat distinct in its species and seed size composition. Daphne appears to share this relatively distinct (and as shown earlier, often larger and harder) seed array with the other small, dry island sampled, Hermanos III.

\section{Temporal changes in finch feeding behaviour}

Figure 7 shows changes between July 1975 and June 1978 in the proportion of feeding in nine food categories by $G$. fortis and scandens (see also Boag \& Grant, 1984). The lower histograms show proportions of feeding in four main resource categories (soft, medium, and hard seeds as defined earlier, and Opuntia flower pecking), while the upper histograms give proportions for the other five categories, whenever they constituted $5 \%$ or more of the total feeding records for a species.

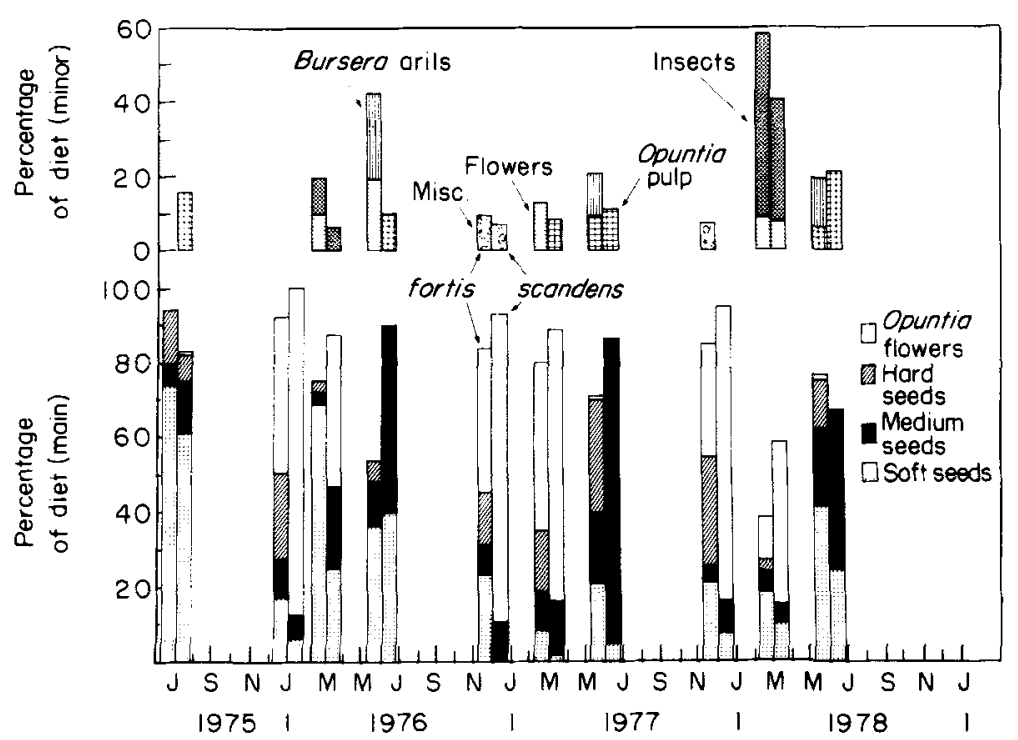

Figure 7. Diets of $G$. fortis and scandens during the Daphne Major study. The left column at each study period shows the proportion of feeding records for $G$. fortis in nine feeding categories, while the right columns provide similar information for scandens. The categories are discussed in Boag \& Grant (1984); "flowers" includes leaves, seedlings, and flowers of all plants other than Opunita, while "misc." includes seabird offal such as broken eggs and fish scraps. 


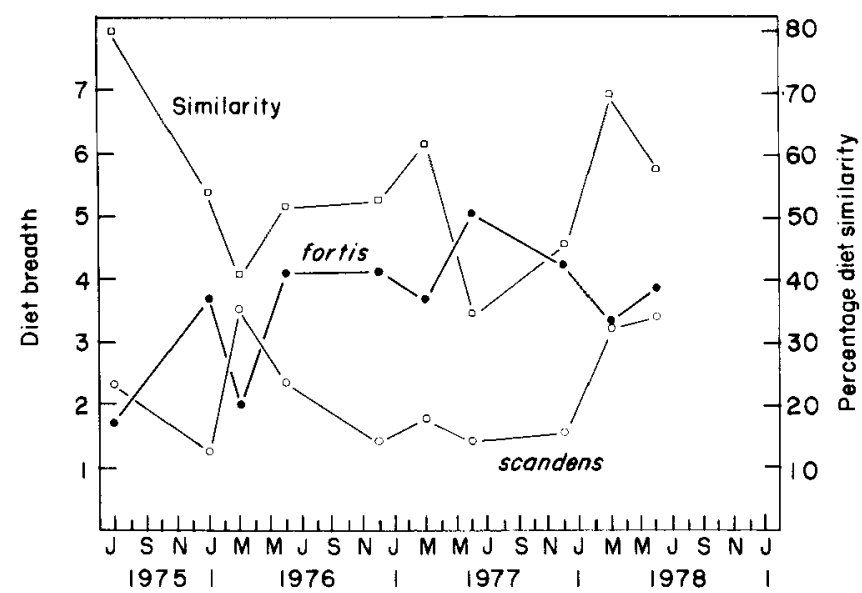

Figure 8. Chronological changes in the diet breadths of $G$. fortis and scandens on Daphne, and in diet similarity between the two species. Diet breadth is $1 / \Sigma p_{i}^{2}$ (Rotenberry, 1980). Diet similarity is $\Sigma$ $\min .\left(p_{1}, p_{2} i\right)$ (Whittaker, 1960).

The most conspicuous feature of the feeding of both fortis and scandens on Daphne was the seasonal switch into and out of Opuntia flower feeding. This is a function of the flowering phenology of Opuntia; by April or May there were few Opuntia flowers left on Daphne. When Opuntia flowers were scarce, fortis typically switched to a diet of small seeds, with some large seeds, while scandens changed to medium seeds (primarily Opuntia seeds extracted from ripe fruits), with some small seeds.

Earlier we saw that the seed distribution on Daphne changed in 1977, and it is when Opuntia flowers are scarce and there are few small seeds, that key changes in feeding behaviour are observed. Small seed abundance in the diets of both species declined as the availability of small seeds declined; the correlation between the proportion of small seeds in the diet and the proportion of the available seed biomass represented by small seeds was $0.79(\mathcal{N}=9, P<0.02)$ for fortis and 0.72 for. scandens $(\mathcal{N}=9, P<0.05)$. Thus in June 1977 scandens became a specialist on Opuntia seeds while fortis maintained a mixed seed diet, with an unusually high utilization of hard seeds. The percentage of total fortis diet consisting of hard seeds in June 1977 was $30.4 \%$, compared to $14.2 \%$ in July 1975, 5.8\% in May-June 1976 and 13.3\% in May-June 1978.

These changes are illustrated by Fig. 8, which shows how the diet breadth of each species and the diet similarity between the two species changed. Geospiza fortis had a narrow diet when small seeds were abundant, and a wider diet when small seeds became scarce; the correlation between small seed abundance and fortis diet width was $r=-0.70(\mathcal{N}=10, P=0.023)$. G. scandens had a wide diet when small seeds were abundant, and a narrow diet when they were uncommon $(r=0.61, \mathcal{N}=10, P=0.061)$.

Diet overlap changes may reflect changes in the relative abundance of food items as much as shifts in the foraging of individuals caused by competition (Hurlbert, 1978; Lawlor, 1980). We repeated the above analyses by examining temporal changes in the similarity between seed feeding and availability in three $\sqrt{D H}$ categories (see Boag \& Grant, 1984). Once again fortis showed a clear 
tendency towards dietary generalization during 1977 while scandens showed the reverse trend.

Such results suggest that fortis was responding to intraspecfic competition while scandens responded to interspecific competition (Smith et al., 1978). As in other field studies, the main difficulty is reducing availability and utilization estimates of seeds, flowers, insects, Bursera arils, etc., to a common currency. One approach is to use stepwise multiple regression to establish the extent to which increased numbers of one species predict decreases in the numbers of a putative competitor (Hallett \& Pimm, 1979). Several such analyses were carried out using data in Boag (1981), but the best predictor of one species' population size (either fortis or scandens) was usually the population size of the other species, even when covariates such as seed abundance or rainfall were forced into the regressions first.

\section{Correlations between the environment and morphology}

Given the population decline in 1977 and its association with changes in resources and in foraging behaviour, we now turn to evidence for correlated changes in phenotypes. Figure 4, discussed earlier, summarized the most obvious change, namely that by 1978 the average size of Daphne fortis had increased, and there were virtually no fuliginosa and fuliginosa-like fortis left on the island.

This shift is better illustrated as a chronological trend (Fig. 9). Principal component I ("body size"; Blackith \& Reyment, 1971) increased steadily during the 1977 drought, whether one considers the entire adult population or smaller subsamples of males or females alone. Much the same pattern is seen in other univariate or multivariate characters (Table 4). Statistics for 10 variables in six groups of finches over 11 study periods are available in Boag (1981); the same data has been deposited with the British Museum and are available from the authors. Table 4 summarizes changes in the means and variances of all adults, males alone, and females alone, between June 1976 and March 1978. Changes in variance were small for $G$. fortis, with none statistically significant. Changes in the means of most characters were significant and in the direction expected if larger birds survived best.

The results for $G$. scandens survival from 1976 to 1978 were different (Fig. 9). There were again changes in means, with a tendency towards higher survival of larger individuals, but the effect was less obvious than in fortis. On the other hand, there were large, and significant reductions in variance for many scandens characters between 1976 and 1978 (Table 4). Discriminant analyses were less successful in separating scandens survivors from nonsurvivors compared to fortis, and emphasized different characters (Table 4). Taken together, the data argue for more stabilizing selection in scandens than in most of the fortis groups, where directional selection predominated. A similar dichotomy in Daphne fortis and scandens selection regimes was seen in an independent data set described by P. R. Grant et al. (1976). Although the standard errors are large, Fig. 9 suggests some convergence between male and female scandens morphology in June 1977. Such convergence would also indicate the presence of stabilizing selection for an intermediate, 'ecologically optimum' phenotype during the period of food shortage and specialized Opuntia feeding seen in scandens in June 1977. 
Table 4. Statistical tests on before (May 1976) and after (March 1978) selection data

\begin{tabular}{|c|c|c|c|c|c|c|c|}
\hline \multirow[b]{2}{*}{ Group } & \multirow[b]{2}{*}{ Character } & \multicolumn{3}{|c|}{ G. fortis } & \multicolumn{3}{|c|}{$G$. scandens } \\
\hline & & $\begin{array}{l}\text { Mean } \\
\text { change }\end{array}$ & $\begin{array}{c}\text { Variance } \\
\text { change }\end{array}$ & S.D.F.C. & $\begin{array}{l}\text { Mean } \\
\text { change }\end{array}$ & $\begin{array}{l}\text { Variance } \\
\text { change }\end{array}$ & S.D.F.C. \\
\hline \multicolumn{8}{|c|}{ All birds } \\
\hline & WGT & $+7.14^{\ddagger}$ & +0.47 & 0.45 & $+3.47^{+}$ & $-1.80^{*}$ & -0.28 \\
\hline & WNG & $+6.36^{+}$ & -1.12 & 0.35 & $+2.99^{\dagger}$ & $-1.67^{*}$ & -0.22 \\
\hline & TRS & $+4.65^{*}$ & -1.16 & 0.13 & $+2.48^{\dagger}$ & -1.47 & 0.06 \\
\hline & BLG & $+5.29^{\ddagger}$ & +1.06 & 0.14 & +1.94 & $-1.98^{\dagger}$ & 0.08 \\
\hline & BDT & $+6.75^{+}$ & +1.04 & 0.45 & $+3.35^{+}$ & $-1.75^{*}$ & 0.36 \\
\hline & BWD & $+5.59^{\ddagger}$ & +1.01 & -0.56 & $+4.68^{+}$ & -1.66 & -1.03 \\
\hline & LA4 & $-4.89^{\ddagger}$ & -1.08 & -0.35 & -1.22 & +1.14 & -0.10 \\
\hline & PCl & $7.28^{*}$ & -1.03 & & $+4.43^{\ddagger}$ & $-2.46^{+}$ & \\
\hline & $\mathrm{PC2}$ & -1.34 & +1.02 & & -0.96 & +1.04 & \\
\hline & $\mathrm{CVl}$ & $-8.45^{\ddagger}$ & -1.03 & & $+3.70^{+}$ & -1.15 & \\
\hline \multicolumn{8}{|c|}{ Males only } \\
\hline & WGT & $+4.07 \ddagger$ & +1.33 & 0.85 & +0.72 & -1.46 & 0.08 \\
\hline & WNG & +1.41 & +1.09 & -0.37 & -0.32 & -1.05 & 0.55 \\
\hline & TRS & +1.27 & +1.02 & -0.07 & +1.16 & $-2.11 *$ & -0.27 \\
\hline & BLG & $+2.82^{\dagger}$ & -1.14 & -0.29 & -0.25 & -1.28 & 0.02 \\
\hline & BDT & $+4.36^{\ddagger}$ & -1.12 & 1.00 & +1.53 & $-2.06 *$ & 0.23 \\
\hline & BWD & $+3.53^{\ddagger}$ & -1.12 & -0.56 & $+2.24^{*}$ & $-2.14^{*}$ & -1.18 \\
\hline & LA4 & $-2.75^{\dagger}$ & -1.35 & -0.32 & -0.99 & +1.95 & -0.08 \\
\hline & $\mathrm{PCl}$ & $+4.22^{+}$ & -1.16 & & +1.29 & $-2.35 *$ & \\
\hline & PC2 & -1.10 & -1.06 & & -1.23 & +1.83 & \\
\hline & GVl & $-5.25^{\ddagger}$ & -1.03 & & +1.52 & -1.80 & \\
\hline \multicolumn{8}{|c|}{ Females only } \\
\hline & WGT & +1.52 & -1.01 & 0.24 & -0.30 & $-3.45^{*}$ & 0.50 \\
\hline & WNG & $+2.10^{*}$ & +1.53 & -0.19 & +1.12 & -1.69 & -0.48 \\
\hline & IRS & +1.51 & +1.22 & -0.11 & +0.22 & -1.06 & 0.26 \\
\hline & BLG & $+2.02 *$ & +1.16 & -1.21 & +0.22 & $-7.46^{\dagger}$ & -0.08 \\
\hline & BDT & $+2.28^{*}$ & -1.26 & 0.55 & +1.57 & -1.96 & -0.14 \\
\hline & BWD & $+2.01^{*}$ & +1.37 & 0.26 & +1.70 & -2.22 & -0.67 \\
\hline & LA4 & $-2.93^{\dagger}$ & -1.01 & 0.90 & -1.11 & -1.33 & 0.18 \\
\hline & PCl & +2.43 & +1.08 & & +0.86 & $-6.19^{+}$ & \\
\hline & $\mathrm{PC} 2$ & -1.87 & -1.00 & & -1.17 & -1.89 & \\
\hline & GVI & $-3.62^{\ddagger}$ & +1.51 & & +1.56 & $-3.10^{*}$ & \\
\hline
\end{tabular}

Mean and variance changes are summarized by $t$ - and $F$-tests calculated from independent samples of finches surviving and not surviving between June 1976 and March 1978. Tests for combined survivors and non-survivors versus survivors are given in Boag (1981). The direction of change is given by the sign preceding $t$ and $F$ values. The principal component ( $\mathrm{PCl}$ and $\mathrm{PC} 2)$ and canonical variate (CV1) analyses are described in Boag (1981) and Boag \& Grant (198I). The standardized discriminant function coefficients (S.D.F.C.) show the relative importance of each character in each canonical variate. ${ }^{*} P<0.05,{ }^{\dagger} P<0.01,{ }^{\ddagger} P<0.001$.

To assess selection intensity, we used O'Donald's methods (1970, 1973; Cook \& O'Donald, 1971). These lead to two types of selection index, the first being $I=\left(w_{\theta}-\bar{w}\right) / w_{\theta}$, where $I$ is the amount by which fitness (operationally defined as survival) is reduced because the average fitness of the population $(\bar{w})$ is below the fitness displayed by some optimum phenotype in the population $\left(w_{\theta}\right)$. The second index is $\Delta \bar{w} / \vec{w}$, or the increase in mean relative fitness of the population as the result of selection.

When selection is at least partly normalizing, and an optimum phenotype $(\theta)$ is present in the population, a quadratic fitness function is used to model 


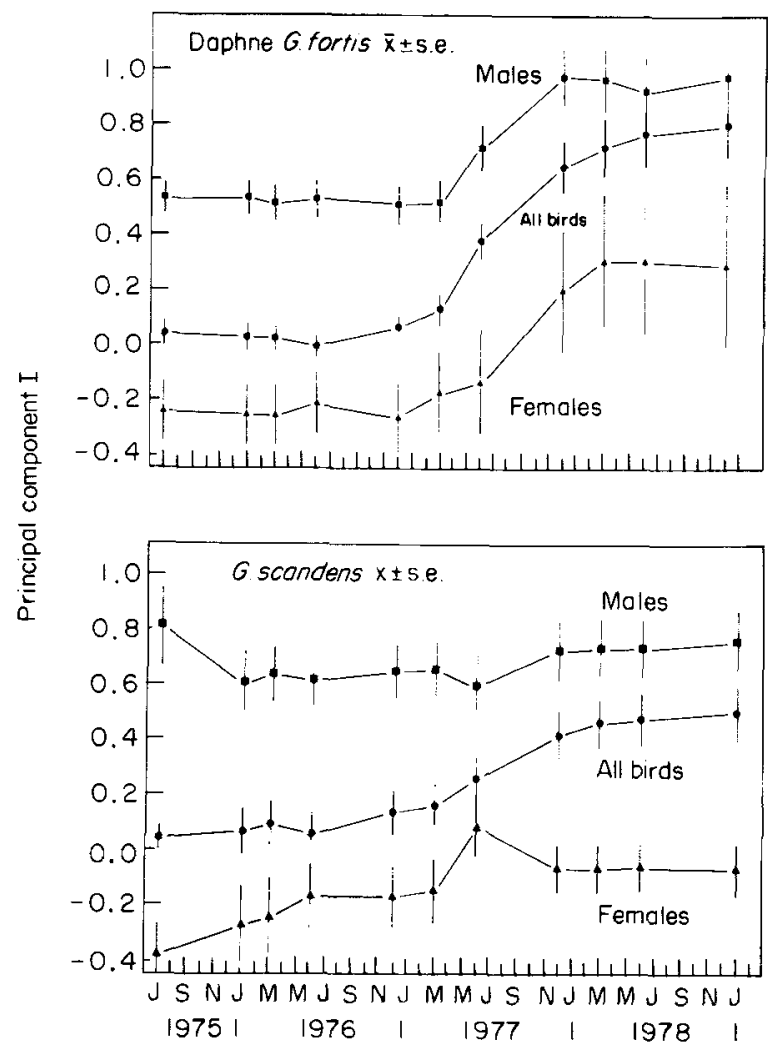

Figure 9. Temporal changes in Daphne G. fortis and scandens principal component I ('body size'). See also Tables 4 and 5 .

phenotype specific survival. When selection is primarily directional, and an optimum is not present in the population, $I$ becomes undefined and a linear fitness function can be assumed, where $\Delta \bar{w} / z \bar{w}=\left(\Delta \bar{x}^{2}\right) / V_{x^{\prime}}$ or the ratio of the squared change in the phenotypic mean to the original population variance of that character. The latter is the square of the quantitative genetic index of selection intensity (i) (O'Donald, 1970).

Table 5 summarizes values of $\Delta \bar{w} / \bar{w}$ based on the linear model for fortis, and $\theta$, $I$ and $\Delta \bar{w} / \bar{w}$ based on both quadratic and linear models for scandens. Although the linear model for $\Delta \bar{w} / \bar{w}$ is most relevant for G. fortis, $\Delta \bar{w} / \bar{w}$ values generated by other models (see Boag, 1981) were not very different. In most cases there was also good agreement between the two selection models for scandens $\Delta \bar{w} / \bar{w}$ values; the $\theta, I$ and $\Delta \bar{w} / \bar{w}$ values produced by the quadratic and a related 'noroptimal' model (not shown) were also similar (O'Donald, 1973; Boag, 1981). The main conclusion is that strong selection took place in both species; our results contain $I$ and $\Delta \bar{w} / \bar{w}$ values larger than those for strong selection on house sparrows (Passer domesticus) collected by $\mathrm{H}$. Bumpus after a winter storm (O'Donald, 1973).

The shapes of the fitness functions can be empirically determined (Fig. 10), although large sample sizes are needed to achieve reliable results (Hagen \& Gilbertson, 1973). Here data such as those in Fig. 4 have been used to estimate 

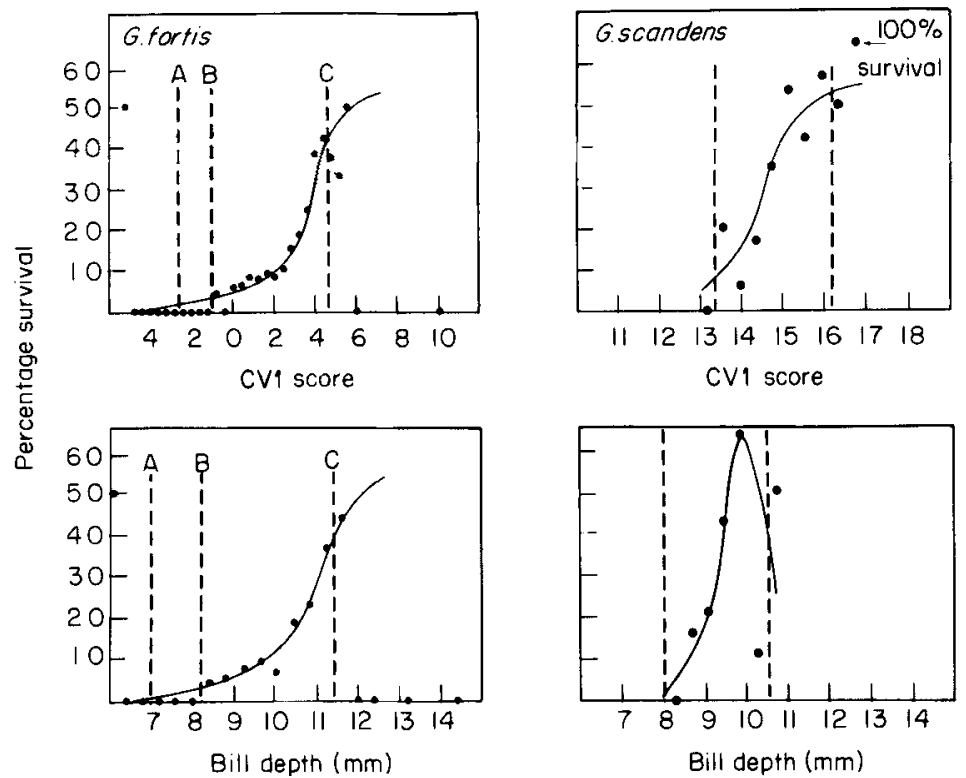

Figure 10. Left: Plots showing the relative survival ('fitness') of different sizes of Daphne fortis and fuliginosa between June $1976(N=734)$ and March 1978. The veil lines indicate that less than $2 \%$ of all 1976 Geospiza fell to the left of A, that less than $2 \%$ of the birds originally called fortis fell to the left of B, and that less than $2 \%$ of the combined 1976 fortis and fuliginosa populations fell to the right of $\mathrm{C}$. The curves were drawn by eye. Only one fuliginosa survived to 1978 ; this is at the $50 \%$ survival level because only one other bird was in its original size class. Right: Survival curves for G. scandens between June $1976(\mathcal{N}=152)$ and March $1978(\mathcal{N}=49)$. Veil lines indicate the upper and lower $2 \%$ of the 1976 sample. The point at $100 \%$ in the upper plot has been lowered, and represents a single individual in that $1976 \mathrm{CVl}$ score class. (See Table 4 for CV1 analyses).

the relative survival rates of different sized finches, which have been plotted against their phenotypic values. Small fortis have low survival until the fitness curve enters a rapid climb towards the optimum, with a suggestion of a tapering off in a sigmoidal fashion at the largest phenotypes. Geospiza scandens displayed a faster increase in survival rate with size, reaching optima not that distant from the original population mean. For some characters scandens appeared to have reduced survival in the largest individuals, but our sample sizes were small.

Figure 9 and Table 5 show that fortis females experienced stronger selective mortality than males, expected given that the sex ratio became skewed in favour of males (Boag \& Grant, 1984). The overall effect of selection in the two sexes was similar, but slightly different aspects of 'largeness' were favoured in males compared to females. Male discriminant coefficients and $\Delta \bar{w} / \bar{w}$ values emphasized selection on bill depth and weight, while in females bill length, bill LA4, and bill depth were emphasized (Boag \& Grant, 1981). Also, the change in PC2 scores in males was not significant, whereas females experienced a decrease approaching significance $(P=0.06)$, and a larger $\Delta \bar{w} / \bar{w}$ value of 0.17 (Tables 4, 5). A PC2 score decrease indicates that the bill of female survivors was less pointed (Boag, 1981).

Why did larger, male fortis survive so much better during the 1977 drought? One explanation is that small fortis disappeared because of the reduced abundance of small seeds on Daphne in 1977. When fortis were classified according to the largest, hardest type of seed they were ever observed to feed on 
Table 5. Estimates of selection intensities for Daphne Geospiza. See text for details

\begin{tabular}{|c|c|c|c|c|c|c|}
\hline \multirow[b]{2}{*}{ Group } & \multirow[b]{2}{*}{ Character } & \multirow{2}{*}{$\begin{array}{c}G . \text { fortis } \\
\text { Linear model } \\
\Delta \bar{w} / \bar{w}\end{array}$} & \multicolumn{4}{|c|}{ G. scandens } \\
\hline & & & $\theta$ & $\begin{array}{c}\text { Quadratic model } \\
I\end{array}$ & $\Delta \bar{w} / \bar{w}$ & $\begin{array}{c}\text { Linear model } \\
\qquad \Delta \bar{w} / \bar{w}\end{array}$ \\
\hline \multicolumn{7}{|l|}{ All birds } \\
\hline & WGT & 0.485 & 23.794 & 0.319 & 0.145 & 0.125 \\
\hline & WNG & 0.388 & 74.427 & 0.227 & 0.124 & 0.097 \\
\hline & TRS & 0.220 & 23.545 & 0.359 & 0.085 & 0.081 \\
\hline & BLG & 0.278 & 14.864 & 0.153 & 0.082 & 0.040 \\
\hline & BDT & 0.438 & 9.806 & 0.263 & 0.160 & 0.118 \\
\hline & BWD & 0.307 & 9.753 & 0.422 & 0.241 & 0.224 \\
\hline & LA4 & 0.235 & 5.352 & -0.171 & 0.025 & 0.020 \\
\hline & $\mathrm{PGl}$ & 0.500 & 3.583 & 0.442 & 0.191 & 0.180 \\
\hline & $\mathrm{PC} 2$ & 0.018 & 7.139 & -0.680 & 0.013 & 0.012 \\
\hline & GVl & 0.662 & 17.664 & 0.517 & 0.174 & 0.171 \\
\hline \multicolumn{7}{|l|}{ Males only } \\
\hline & WGT & 0.198 & 21.864 & 0.123 & 0.029 & 0.008 \\
\hline & WNG & 0.025 & 70.600 & 0.051 & 0.002 & 0.002 \\
\hline & TRS & 0.021 & 21.125 & 0.179 & 0.087 & 0.021 \\
\hline & BLG & 0.099 & 14.449 & 0.084 & 0.011 & 0.001 \\
\hline & BDT & 0.224 & 9.758 & 0.193 & 0.095 & 0.035 \\
\hline & BWD & 0.151 & 9.110 & 0.206 & 0.124 & 0.072 \\
\hline & LA4 & 0.094 & 4.903 & -0.194 & 0.063 & 0.016 \\
\hline & $\mathrm{PCl}$ & 0.210 & 1.018 & 0.180 & 0.097 & 0.025 \\
\hline & PC2 & 0.016 & -1.223 & -1.181 & 0.325 & 0.122 \\
\hline \multirow{11}{*}{ Females only } & CVl & 0.311 & 30.262 & 0.181 & 0.081 & 0.035 \\
\hline & WGT & 0.117 & 19.638 & 0.209 & 0.145 & 0.003 \\
\hline & WNG & 0.216 & 72.711 & 0.185 & 0.079 & 0.042 \\
\hline & TRS & 0.115 & 17.730 & -0.103 & 0.002 & 0.002 \\
\hline & BLG & 0.201 & 14.268 & 0.205 & 0.176 & 0.001 \\
\hline & BDT & 0.251 & 9.336 & 0.291 & 0.182 & 0.078 \\
\hline & BWD & 0.199 & 8.775 & 0.298 & 0.213 & 0.091 \\
\hline & LA4 & 0.396 & 4.195 & 0.205 & -0.044 & 0.040 \\
\hline & $\mathrm{PCl}$ & 0.282 & -0.123 & 0.189 & 0.169 & 0.023 \\
\hline & $\mathrm{PC} 2$ & 0.174 & -0.313 & 0.171 & 0.080 & 0.045 \\
\hline & CVI & 0.570 & 32.749 & 0.346 & 0.312 & 0.073 \\
\hline
\end{tabular}

(soft, medium, or hard seeds), birds eating harder seeds were found to be larger (Table 6). We also grouped all fortis into two groups according to the largest class of seed they were ever seen to feed on $(\sqrt{\mathrm{DH}}<1.0 v . \sqrt{\mathrm{DH}} \geqslant 1.0)$, and carried out a discriminant analysis. The hard seed feeders were significantly larger than the small seed eating finches $\left(F_{7,311}=7.94, P<0.001\right)$, with the discriminant function weighting bill depth $(0.80)$ and wing $(0.57)$ most heavily. Similar trends are thus apparent in the large group of birds including males, females, and individuals of unknown sex, as well as in smaller groups of males or females alone. There was also a difference in the frequency with which males and females fed in the three seed size categories (Boag \& Grant, 1984). Table 7 shows that significantly more males were recorded having large, hard seeds as their maximum size food than females $\left(\chi_{2}^{2}=8.94, P<0.02\right)$. There is a potential bias in these data because of the skewed sex ratio that developed, but examination of smaller subsets of the data suggests that this was not serious enough to alter our conclusions (Boag, 1981).

We have assumed that the finches disappearing during 1977 perished on Daphne, but some Daphne finches could have emigrated. P. R. Grant, Price \& 
Table 6. Bill depth measurements of G. fortis feeding on soft, medium, and hard seeds. Individuals were classified into the largest seed category they were ever seen to feed on and then the groups compared

\begin{tabular}{lrrr}
\hline & $\mathcal{N}$ & $\bar{X} \pm$ S.E. & $F$-ratio and probability of AOV \\
\hline All Birds & & & \\
$\quad$ Soft Seed & 199 & $9.28 \pm 0.06$ & \\
Medium Seed & 39 & $9.73 \pm 0.12$ & $F=22.39, d f=2,317, P<0.0001$ \\
$\quad$ Hard Seed & 82 & $9.95 \pm 0.08$ & \\
Males Only & & & \\
$\quad$ Soft Seed & 61 & $9.62 \pm 0.12$ & \\
$\quad$ Medium Seed & 22 & $9.71 \pm 0.17$ & $F=3.64, d f=2,134, P=0.029$ \\
$\quad$ Hard Seed & 54 & $10.03 \pm 0.09$ & \\
Females Only & & & \\
$\quad$ Soft Seed & 37 & $9.09 \pm 0.12$ & \\
$\quad$ Medium Seed & 5 & $9.38 \pm 0.55$ & $F=1.29, d f=2,51, P=0.284$ \\
$\quad$ Hard Seed & 12 & $9.50 \pm 0.23$ & \\
\hline
\end{tabular}

Table 7. Frequencies of male and female G. fortis feeding on soft, medium, and hard seeds. Individuals of known sex were classified into the hardest seed group they were seen to feed on

\begin{tabular}{lcccc}
\hline & $\begin{array}{c}\text { Males } \\
\text { frequency }\end{array}$ & Percentage & $\begin{array}{c}\text { Females } \\
\text { frequency }\end{array}$ & Percentage \\
\hline Soft seed & 61 & $(44.5)$ & 37 & $(68.5)$ \\
Medium seed & 22 & $(16.1)$ & 5 & $(9.3)$ \\
Hard seed & 54 & $(39.4)$ & 12 & $(22.2)$ \\
TOTAL & 137 & & 54 & \\
\hline
\end{tabular}

Snell (1980) report the only documented finch emigration from Daphne Major; two ringed juvenile $G$. scandens hatched on Daphne Major during 1979 were seen later that year on Daphne Minor, $6 \mathrm{~km}$ north of Daphne Major. Prevailing winds (Fig. 2) make immigration to Daphne from Santa Cruz or Baltra more likely than vice versa, and Daphne birds would have to fly much further to make landfall in the opposite direction. Finches observed in June 1977 were in poor condition (Boag \& Grant, 1984), with worn plumage. This resulted from a failure of some individuals to moult, coupled with matting of feathers by Chamaesyce latex and Opuntia pulp, and wear from digging in the soil for seeds. Figure 3C shows female fortis No. 356, found dying on 31 May 1977. This bird was ringed in July 1975 as an adult and bred in 1976. It weighed $16.0 \mathrm{~g}$ in July 1975 , but only $11.7 \mathrm{~g}$ in May 1977 , a weight loss of over $25 \%$. Its bill depth was $8.8 \mathrm{~mm}$, placing it at the smaller end of the bill depth distribution in Fig. 4A, resulting in a survival probability of only $6 \%$ based on the fitness functions in Fig. 10.

Furthermore, the measurements of $38 \mathrm{G}$. fortis adults caught and ringed before June 1976 and found dead on Daphne in 1977 and early 1978 were statistically similar to the other birds missing from the post-selection population (Table 8). The individuals found dead were also significantly smaller than the 1978 survivors. The elevated variability of the males found dead was not found 
Table 8. Measurements of male $G$. fortis found dead on Daphne in 1977 and 1978 compared to males which disappeared but were not found

\begin{tabular}{|c|c|c|c|c|c|c|}
\hline \multirow[b]{2}{*}{ Character } & \multicolumn{2}{|c|}{ Found dead } & \multicolumn{2}{|c|}{ Missing } & \multicolumn{2}{|c|}{ Tests } \\
\hline & $\bar{x}$ & $S$ & $\bar{x}$ & $s$ & $t$ & $F$ \\
\hline WGT & 16.37 & 1.60 & 16.40 & 1.28 & 0.10 & 1.56 \\
\hline WNG & 69.00 & 2.38 & 69.40 & 1.95 & 0.81 & 1.49 \\
\hline TRS & 18.83 & 0.76 & 19.10 & 0.66 & 1.64 & 1.31 \\
\hline BLG & 10.82 & 0.96 & 10.91 & 0.68 & 0.42 & $1.96^{*}$ \\
\hline BDT & 9.60 & 1.08 & 9.68 & 0.76 & 0.30 & $2.02 *$ \\
\hline BWD & 8.89 & 0.83 & 8.85 & 0.53 & 0.23 & $2.40^{*}$ \\
\hline $\mathrm{LA} 4$ & 3.49 & 0.32 & 3.51 & 0.30 & 0.25 & 1.10 \\
\hline
\end{tabular}

Means and standard deviations are shown. $t$ - and $F$-tests were based on 19 males found dead and 144 males missing after the 1977 drought but not recovered. Similar results were obtained for 38 males, females and birds of uncertain sex found dead compared to 582 missing birds. ${ }^{*} P<0.05,{ }^{\dagger} P<0.01$.

in the equivalent tests of females or the combined group, and we do not know how to interpret this result. The small number of dead females is surprising in view of the change in sex ratio favouring males during 1977. However, as described in Boag \& Grant (1983), sex ratio estimation is difficult in these populations. A majority of the 16 birds of unknown sex found dead were probably females, and in any case, the sex ratio in the population at the time these particular birds died is not known, but may already have been skewed towards males. If individuals did successfully emigrate beyond Daphne Minor, they would be unlikely to return to Daphne Major in significant numbers, and thus emigration would have the same evolutionary consequences as death on Daphne Major. None of the birds missing in 1977 have reappeared since.

\section{Relative importance of hybridization and selection}

Earlier it was shown that small numbers of fuliginosa are regularly present on Daphne, that they mate with Daphne fortis in small numbers, and produce offspring intermediate in size to the two parents. Little work has been done on quantitative genetic models of hybridization per se, and while traditional population genetics theory predicts that small amounts of gene flow can counteract the evolutionary effects of genetic drift or mutation, the relationship between gene flow and selection is more difficult to predict (Wilson \& Bossert, 1971; Roughgarden, 1979). As a first step in quantifying the potential impact of hybridization on the Daphne fortis phenotype, we simulated several different hybridization regimes using a simple deterministic 'dilution' model of introgression.

Thus $\bar{x}_{t+1}=\left(\bar{x}_{i}(100-H)+H\left(\bar{x}_{t}+\bar{y}\right) / 2\right) / 100$, where $\bar{x}_{t}$ and $\bar{x}_{t+1}$ are the character means of the fortis population before and after one generation of hybridization, $H$ is the percentage of interspecifically mating pairs, and $\bar{y}$ is the character mean of the immigrant fuliginosa. When iterated, the model shows how the Daphne population mean changes over successive generations of different percentages of interspecific mating. In effect it assumes the absence of sexual dimorphism, that a pair replaces itself by two identical offspring in one generation, that the heritability of the trait is one, and that interspecific pairs and their offspring have the same reproductive output and survival as normal 


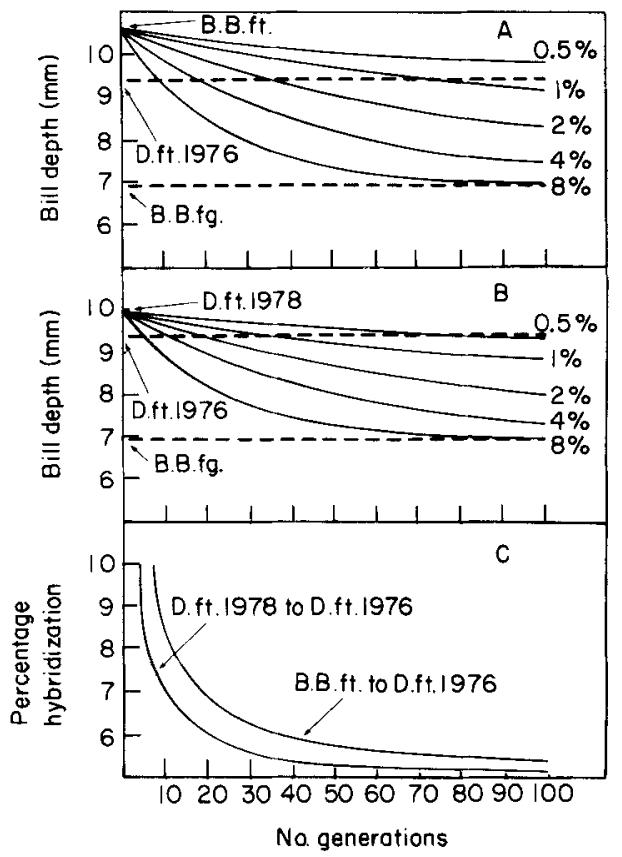

Figure 11. Simulation of $G$. fortis-G. fuliginosa introgression. See text for details. A, Morphological change (bill depth in $\mathrm{mm}$ ) over time (generations) if Bahía Borrero fortis mated with Bahía Borrero fuliginosa at five rates of introgression. The upper broken line indicates the mean bill depth of 1976 Daphne fortis, while the lower broken line indicates the mean bill depth of Bahia Borrero fuliginosa. B, Morphological changes resulting from introgression between Daphne fortis having the large, 1978 post-selection bill depth, and Bahia Borrero fuligingsa. Broken lines as above. C, The relationship between different rates of introgression and the time to either shift the Bahía Borrero fortis to 1976 Daphne fortis or to shift the 1978 Daphne fortis bill depth back to its 1976 value.

pairs and their offspring. Despite the simplicity of the approach, the results should provide a conservative upper limit to the effects of hybridization, because most assumptions would be violated in directions reducing the rate of gene flow and ensuing morphological change.

Figure 11 shows the results of several different simulations over 90 generations, using bill depth in $\mathrm{mm}$. Matings between Santa Cruz fortis $(\bar{x}=10.56 \mathrm{~mm})$ and Santa Cruz fuliginosa $(\bar{x}=6.91 \mathrm{~mm})$, suggest that a Daphne phenotype would be reached after only 7 generations of $10 \%$ hybridization, but that a $1 \%$ rate would require over 70 generations (Fig. 11A) (we assume a mean generation time of 3-5 years in fortis (Boag \& Grant, 1984)). Figure $11 \mathrm{~B}$ is similar, but shows the time courses for hybridization between Daphne fortis as measured in March $1978(\bar{x}=9.96 \mathrm{~mm})$ and Santa Cruz fuliginosa, again suggesting that the 1976, pre-drought Daphne fortis mean bill depth $(\bar{x}=9.42 \mathrm{~mm})$ could be reached after only three generations of $10 \%$ hybridization, but that about 40 generations of $1 \%$ hybridization would be needed. The results of such dynamic analyses are summarized in Fig. $11 \mathrm{C}$ which uses static isoclines to show how the length of time to go from either a large Santa Cruz fortis to a 1976 Daphne fortis or from a 1978 Daphne fortis to a 1976 fortis is a decreasing function of hybridization frequency, with frequencies less than $2 \%$ probably requiring well over a century to produce substantial changes in fortis means. 
Table 9. Patterns of bill depth variation in Geospiza at central Galápagos sites

\begin{tabular}{|c|c|c|c|c|}
\hline Species & Site and data source & $\begin{array}{c}\text { Mean bill } \\
\text { depth in mm }\end{array}$ & C.V. & $\mathcal{N}$ \\
\hline \multicolumn{5}{|l|}{ G. fortis } \\
\hline & Bahía Academía (Lack, 1945) & $12.62^{*}$ & 9.91 & 148 \\
\hline & Bahía Academía (Abbott et al., 1977) & 11.09 & 11.18 & 39 \\
\hline & Bahía Academía (unpubl., Jul. 1975) & 10.99 & 11.74 & 73 \\
\hline & Bahía Tortuga (unpubl., May 1977) & 10.84 & 12.14 & 84 \\
\hline & Cerro Colorado (unpubl., May 1977) & 10.45 & 9.59 & 106 \\
\hline & Plaza Sur (Abbott et al, 1977) & 10.50 & 6.24 & 11 \\
\hline & Seymour (Lack, 1945) & $12.26^{*}$ & 7.63 & 48 \\
\hline & Bahía Borrero (Abbott et al., 1977) & 10.68 & 6.99 & 76 \\
\hline & Bahía Borrero (unpubl., Jul. 1975) & 10.56 & 7.79 & 86 \\
\hline & Daphne (Lack, 1945) & $10.51 *$ & 7.36 & 37 \\
\hline & Daphne (Abbott et al., 1977) & 9.40 & 8.30 & 57 \\
\hline & Daphne (unpubl., July 1975) & 9.47 & 7.92 & 215 \\
\hline & Daphne (unpubl., June 1976) & 9.42 & 8.75 & 642 \\
\hline & Daphne (unpubl., June 1978) & 10.02 & 7.68 & 68 \\
\hline & Cerro Ballena (unpubl., July 1975) & 9.69 & 7.56 & 26 \\
\hline \multicolumn{5}{|c|}{ G. fuliginosa } \\
\hline & Bahía Academía (Lack, 1945) & $8.00^{*}$ & 5.00 & 113 \\
\hline & Bahía Academía (Abbott et al., 1977) & 7.00 & 4.60 & 40 \\
\hline & Bahía Tortuga (unpubl., May 1977) & 7.05 & 4.13 & 28 \\
\hline & Cerro Colorado (unpubl., May 1977) & 6.83 & 4.41 & 25 \\
\hline & Seymour (Lack, 1945) & $7.97 *$ & 4.69 & 58 \\
\hline & Bahía Borrero (Abbott et al., 1977) & 7.00 & 4.60 & 80 \\
\hline & Bahía Borrero (unpubl., July 1975) & 6.91 & 3.90 & 96 \\
\hline & Daphne (unpubl., June 1976) & 7.00 & 8.52 & 31 \\
\hline & Cerro Ballena (unpubl., July 1975) & 6.81 & 4.32 & 78 \\
\hline & Hermanos [Crossmans] (Lack, 1945) & $9.48^{*}$ & 8.74 & 14 \\
\hline & Isla Tortuga (unpubl., July 1975) & 7.39 & 5.84 & 18 \\
\hline
\end{tabular}

C.V. is the coefficient of variation. Samples generally contained mature finches, including males, females and birds of uncertain sex. Lack's (1945) data have asterisks beside their bill depths because he measured total depth, while our data are for depth at nares. Lack's data are the average for male and female subsamples. See Fig. 2 for site locations.

\section{Overall morphological variability of Daphne fortis}

Table 9 summarizes the means and coefficients of variation (CV) of bill depth in several different fortis populations; bill depth, because it displays positive allometry, is particularly sensitive to changes in population variation (Boag, 1984). One characteristic of natural hybridization is increased variability in the hybridizing population (Schueler \& Rising, 1976), but Daphne does not appear to have an extraordinarily variable fortis population. CVs of $7-8 \%$ are high compared with most passerines, but fortis are quite variable across the archipelago (P. R. Grant \& Schluter, 1983). P. R. Grant et al. (1976) suggested that Daphne fortis were less variable than Santa Cruz fortis because of reduced food and environmental diversity on Daphne, but this is really only true if one chooses Bahía Academía fortis as the typical Santa Cruz fortis. Bahía Academía fortis are unusually large and variable compared to other fortis populations in the archipelago. This may represent introgression with G. magnirostris (Snow, 1966), unusually strong disruptive selection in the Bahía Academía environment (Ford, Parkin \& Ewing, 1973), or introgression of genes from immigrant fortis from another island (P. R. Grant et al., 1976). 
Our data show that fortis populations measured at Bahía Tortuga, about $5 \mathrm{~km}$ west of Bahía Academía, have morphology similar to that seen at Bahía Academía. Geospiza fortis measured at Plaza Sur show less variation than fortis on southern Santa Cruz, although in 1977 finches at Cerro Colorado, on Santa Cruz adjacent to Plaza Sur, did not show nearly as large a decline in variation. Other fortis populations, such as that at Cerro Ballena on Isla Isabela, show levels of variation more like those at Bahía Borrero. Geospiza fuliginosa populations are in general about half as variable; conspicuous exceptions in Table 9 include the Daphne and Hermanos fuliginosa. This suggests that introgression with fortis may have had relatively more effect on these populations. Daphne fortis display levels of morphological variation more or less comparable to the fortis on northern Santa Cruz, such as at Bahía Borrero (Fig. 2).

\section{DISCUSSION}

\section{Genetic drift}

Non-adaptive effects such as genetic drift appear unlikely to be a major force in the evolution of Daphne fortis morphology. The population is periodically reduced to numbers at which drift could be important (Boag, 1983), but in 1977 such a reduction was associated with strong selection. The long-term, high degree of isolation required for drift or founder effect to act also seems lacking. However, compared to other small islands like Rocas Bainbridge, Cowley, or Champion-near-Floreana (Fig. 2), Daphne is probably isolated enough so that stronger, adaptive processes stand a chance of altering Daphne phenotypes without continually being swamped by immigration. The isolation and population size reductions may also be sufficient to encourage drift in more ecologically 'neutral' characters, such as song dialects.

For instance, Ratcliffe (1981) showed that the song dialects of both Daphne fortis and scandens are distinct compared to other populations of the same species; multivariate analyses actually place both species' dialects close to those of the same species on Isla Rabida (Fig. 2). There is an indication that the plumage of Daphne Geospiza may be duller than in Santa Cruz Geospiza, but the difference is subtle and has not been examined quantitatively (Boag, 1981). Geospiza nestlings also display a bill-colour polymorphism (P. R. Grant, Boag \& Schluter, 1979), but there is no indication that the frequency of the distinctive yellow morph is different on Daphne compared to surrounding islands. Neither fortis nor scandens display any other unique behavioural or physical characteristics, such as the unusual feeding habits seen in some ground finch populations (Bowman \& Billeb, 1965; Carpenter, 1966; MacFarland \& Reeder, 1974). Relatively little detailed biochemical or karyotypic work has been carried out on the finches (Polans, 1975; Jo, 1976; Ford et al., 1974; Yang \& Patton, 1981), and none on Daphne.

\section{Hybridization}

Traditional population genetics theory (Wilson \& Bossert, 1971; Roughgarden, 1979) predicts that small amounts of gene flow will negate 
population differentiation by drift or mutation. The relationship between gene flow and selection is more complicated, and depends on the relative magnitudes of migration and selection, the type and directions of selection, and whether or not immigration is random or selective (Spieth, 1979). Our data agree with studies suggesting that strong local selection can promote local differentiation even with moderate amounts of gene flow (McPhail, 1969; Endler, 1973; Gibson \& Thoday, 1973; Baker, 1975).

The precise magnitude of gene flow between the Daphne population and fuliginosa or fortis from adjacent islands remains uncertain. Current frequencies of interspecific mating are low and actual gene flow presumably lower, depending on how effectively hybrid offspring are integrated into the Daphne population. Observations on such integration will be important in periods of population expansion such as may occur on Daphne during the especially wet conditions associated with an 'El Nino' event (e.g. 1983) (P. R. Grant \& Boag 1980; Anon., 1983; L. Gibb, pers. comm.). The shortage of females in the population at the end of 1978, together with the ineffective species discrimination of Daphne fortis, could set the stage for higher rates of hybridization if a flock of fuliginosa reached the island during a period of population growth. An increase in the rate of interspecific mating to $10-20 \%$ could result in quite rapid morphological change, and during such a population expansion, selection might favour small individuals because of their higher reproductive output (Dhondt, Eyckman \& Huble, 1979; Johnston \& Fleischer, 1981). Our data do not dismiss the hybridization hypothesis, but suggest that for hybridization to play a major role in shaping the Daphne phenotype, it must periodically be more common, or work in concert with selection pressures opposite to those observed in 1977.

Hybridization may be important in other ways. If smaller phenotypes are sometimes at an ecological advantage on Daphne, hybridization could accelerate the rate at which smaller birds appeared in the population. It could also help maintain relatively high levels of genetic variance in Daphne fortis despite periodic population crashes and selection tending to cull variation. Higher levels of additive genetic variance would result in increased heritabilities of fortis morphology (P. R. Grant \& Price, 1981), permitting the rapid response to directional selection seen in 1977 (Boag, 1983). Soulé \& Stewart (1970) argue that the increased variability seen in some island bird populations (Van Valen, $1965)$ may be due to "occasional genetic input from the mainland subspecies"; this "gene flow-variation hypothesis" (Soulé, 1971) may be one mechanism by which variation in biochemical or other traits is maintained in natural populations (Spieth, 1979). P. R. Grant \& Price (1981) discuss the question of whether hybridization contributes to genetic variance in Daphne fortis in considerable detail. They suggest that such a possibility matches the observations that compared to fortis, the morphologically less variable Daphne scandens have lower heritabilities (Boag, 1983), display little evidence of introgression or immigration, and as shown earlier here, in 1977 were subjected more to stabilizing selection than to directional selection.

In summary, then, we conclude that neither of the 'non-adaptive' hypotheses - genetic drift/founder effect and hybridization-are sufficient to explain the evolution of the Daphne fortis phenotype. 


\section{Food supply}

The 'food supply' or 'floristics' hypothesis stemming from Bowman (1961) is supported in part by our data. There is evidence that Geospiza population sizes on Daphne are closely related to resource levels, which in turn depend on rainfall. As resource levels drop, the frequency distributions of both behavioural and morphological phenotypes change to fit the reduced, changed resource spectrum.

But this hypothesis also predicts that Daphne fortis are small because the local foods are different, and presumably smaller on average than on other fortis islands. This does not seem to be the case, because density-dependent mortality and close resource tracking were associated with natural selection of larger individuals, able to handle the array of larger and hard seeds on Daphne in 1977. Thus the mechanism implied by the hypothesis exists, but it operated in a direction opposite to the predicted one. The limited data available comparing the resource distributions on Daphne with other islands do not support the food supply hypothesis either; the seed environments on Daphne and Hermanos appear similar to each other and somewhat different from sites on larger islands, but these other sites often have more small seeds than Daphne. Abbott et al. (1977: table 10) also found convergence of plant species and seed $\sqrt{\mathrm{DH}}$ similarities among small, dry islands, despite their isolation from each other. Such comparisons need to be improved by collections of additional data. One difficulty is that because of species area relationships, our study area on Daphne represents a more substantial fraction of the total ecological diversity of the island than can similar-sized areas on larger, higher islands (Wiggins \& Porter, 1971). The mobility of finches, particularly in the dry season, means that our food sampling methods underestimate the effective range of resources on large islands because of the missing 'between habitat' or $\beta$ component of diversity (Whittaker, 1972). Studies along altitudinal gradients should help solve this problem (e.g. Schluter, 1982b). Another difficulty is the major influence of the single plant species Tribulus cistoides on the Daphne (and probably also Hermanos) seed environment. Fluctuations in the abundance of this seed alter the seed environment dramatically, but may only affect fortis diets when the preferred small seeds are scarce. Tribulus is an Old World invader (Porter, 1967), further complicating evolutionary interpretations of finch-Tribulus interactions.

\section{Character release}

This hypothesis is by far the hardest to evaluate. Certainly, there is little evidence for the textbook version of character release in which Daphne fortis are pictured as being isolated by chance in allopatry, on an island closely resembling other islands around it except for the absence of congeneric 'sizeneighbours'. Daphne is in the center of the archipelago and receives regular immigrants of several species which have not become resident there. This suggests that there is something about the island itself that leads to a bias in colonization, and that the same characteristics may also have influenced the Daphne fortis phenotype. We have organized our discussion of this hypothesis in the following way. First, we define more fully the predictions of the character release hypothesis. Second, we examine the contemporary evidence for 
correlates of character release on Daphne, i.e. changes apart from the size-shift itself. Third, we examine the neglected problem of whether competition with scandens has influenced the evolution of fortis on Daphne. Fourth, we return to the question of the size-shift and ask why it is that fortis and not fuliginosa became established on Daphne. Lastly, we answer the question of why fortis are small on Daphne, partly by explaining why larger fortis and magnirostris are not found there, and partly by speculating as to the other advantages of being small on the island.

\section{Definitions}

In his original statement of the character release hypothesis, Lack (1947) emphasized only the change in the mean size of fortis on Daphne and fuliginosa on Los Hermanos. Later (Lack, 1969), he added the prediction of "presumed broader niches". P. R. Grant (1972) saw this "ecological release" as an analogue of character release, many examples of which have since been found, with and without accompanying morphological change (Feinsinger \& Swarm, 1982). Van Valen (1965) suggested that missing competitors could also lead to increased morphological variation in island populations, and Arthur (1982) has argued that the term character release should be restricted to such variance changes. Yeaton \& Cody (1974) used the term "competitive release" to mean an increase in the population density of a species in the absence of competitors.

We prefer to restrict the term "character release" to changes in the mean of a morphological character, as distinct from a change in the variance. But rather than argue about definitions, we shall concentrate on the biological process hypothesized by Lack, namely niche expansion in the absence of competitors, and explore its possible manifestations. In birds, the initial phase of a niche expansion is likely to be dominated by behavioural responses, such as expanded diets or habitat preferences, which could either occur through individuals generalizing, or by different individuals specializing on different resources (Van Valen \& Grant, 1970). This could lead to higher population sizes, but no further manifestation of niche expansion would necessarily occur. With more time, however, genetic changes in means or variances of morphological or behavioural characters could take place (Roughgarden, 1972, Slatkin, 1980).

\section{Contemporary correlates of character release}

In addition to size shifts, Daphne fortis might display an increased population density, more variable morphology, or wider diets. As indexed by mist-net captures, Daphne fortis densities are high but no higher than sympatric fortis on islands such as Santa Cruz (Smith el al., 1978). By continental standards, breeding densities on Daphne can also be high (Boag \& Grant, 1984), but there are no comparable data for a fortis population in sympatry, and after the 1977 drought, both total and breeding densities of forties on Daphne were low compared to other sites (Boag \& Grant, 1984). There is little evidence for increased morphological variability on Daphne, and when diet breadths of Daphne fortis were compared with those of other fortis populations at the same time, there was no tendency towards wider diets on Daphne in April 1973, December 1973, or July 1975 (Abbott et al., 1977; Smith et al., 1978; B. R. Grant \& P. R. Grant, 1982; unpublished data). Given the temporal variation seen in Geospiza diet breadths on Daphne, such comparisons may not be very meaningful. 
On Daphne the seasonal changes in scandens diet breadth (Fig. 8) matched those found by Smith et al. (1978) and P. R. Grant \& B. R. Grant (1980a), being positively correlated with the number of plant species $(r=0.94$, $P=0.001)$ or seed species diversity $(r=0.84, P<0.01)$. However seasonal changes in Daphne fortis diet width showed the opposite trend (Fig. 8), being negatively correlated with the observed number of plant species $(r=-0.72$, $P<0.05)$ or seed species diversity $(r=-0.66, P=0.05)$. Increased diet breadth of fortis was also associated with declining food supplies, implying that intraspecific competition for increasingly limited resources was one pressure behind the dietary generalization (Smith et al., 1978).

The strong fluctuations in fortis diet breadth, together with the marked generalization seen when food was short, suggest that ecological release, expressed as diet expansion, may occur on Daphne during very dry seasons or years. Similar dietary expansions may not be seen elsewhere because smaller and larger Geospiza species concurrently specialize on smaller and larger foods. Unfortunately we have not observed the ecology of fortis populations in sympatry under conditions as severe as those observed on Daphne in 1977 and thus do not know whether the Daphne diet expansion is unique (Boag \& Grant, 1981; Schluter, 1982a). There is also the problem that many sympatric fortis populations have the option of dispersing to more humid habitats in the dry season (Schluter, 1982b).

\section{Competition between Daphne fortis and scandens?}

One aspect of the competitive release hypothesis not mentioned in textbooks is the interaction between Daphne fortis and scandens (P. R. Grant \& B. R. Grant, $1980 \mathrm{~b})$. Competition with scandens could have influenced the initial colonization probabilities of fortis compared to fuliginosa, the type of ecological release displayed by fortis on Daphne, or the phenotype eventually adopted by Daphne fortis. It is difficult to demonstrate interspecific competition without experiments, but the indirect evidence for competition between Daphne fortis and scandens is strong. The scandens niche is almost completely included within that of fortis; the only real exceptions are that scandens, unlike fortis, can drill open green Opuntia fruits or unopened Opuntia buds (B. R. Grant \& P. R. Grant, 1981). With time both these resources would become available to fortis.

In most parts of the Galápagos, scandens is an uncommon species, seldom found in areas with low densities of Opuntia (Harris, 1974; Smith et al., 1978). Few sites in the Galápagos have Opuntia and scandens densities as high as those of Daphne. The high relative abundance of Opuntia on Daphne may be a product of the low rainfall there (Boag \& Grant, 1984), as well as the complete absence of browsers such as native tortoises or introduced goats (Racine \& Downhower, 1974). The Opuntia on Daphne seem to ensure a relatively large and stable scandens population on the island, one whose members are aggressively dominant to fortis, and capable of consuming large amounts of soft foods otherwise available to fortis. Furthermore, Daphne scandens are larger than scandens elsewhere (Abbott et al., 1977); this could be either a cause or consequence of Daphne Opuntia seeds being larger than on adjacent Santa Cruz (Abbott et al., 1977). The larger body size may also reflect a pressure to maintain behavioural dominance over fortis on Daphne. In this respect scandens matches the classical description of a species occupying an included niche; included niche species are 
typically aggressive, dominant species, often having highly specialized feeding ecologies (Miller, 1967).

The fact that scandens occupies an included niche must restrict the potential diet expansion of fortis to some degree. The presence of scandens probably also makes it less likely that fuliginosa instead of fortis could have become resident on Daphne. As we shall see later, the fact that scandens can monopolize the majority of the medium size seeds on Daphne when food is short may place fortis on the horns of a dilemma, favouring diet expansion and periodic foraging on large, hard seeds.

\section{Why fortis and not fuliginosa on Daphne?}

Based on species area regressions, Harris (1973) predicts that no more than five landbird species should breed on Daphne, while Abbott et al. (1977) indicate that Daphne is unlikely to have more than two Geospiza species. Thus it is not surprising that only fortis and scandens are resident on Daphne, together with Galápagos doves (Zenaida galapagoensis) and martins (Progne modesta). But this does not tell us why fortis is present and fuliginosa absent; for this we need to look at the autecology of individual species.

One puzzling feature of the Daphne situation is that fortis became small there, instead of fuliginosa having become larger, as on Los Hermanos. This might reflect an element of chance in which species first successfully colonized the island. But all small islands in the archipelago have fuliginosa on them if they have only one Geospiza species (P. R. Grant \& Schluter, 1983). Compared to other Geospiza, fuliginosa populations are remarkably similar to one another, displaying little morphological divergence (Lack, 1945, 1947) or song dialect development (Ratcliffe, 1981). In short, the species is the closest Geospizine equivalent to a "tramp" or "fugitive" species (Diamond, 1975); it is also the "house sparrow" of the Galápagos, being common in villages and other disturbed habitats.

The most likely reason why fuliginosa has not become resident on Daphne is that it cannot survive droughts such as that of 1977. The frequency of droughts on Daphne is not known, but presumably they are more common on Daphne than elsewhere because of the rainshadow from Santa Cruz (Boag \& Grant, 1984; P. R. Grant, 1983b). By 1978, all except one of 33 fuliginosa ringed on Daphne since 1975 had disappeared. Like most of the smaller fortis, the fuliginosa probably disappeared because of the reduced availability of small seeds, flowers, and insects during the 1977 drought. Reports of fuliginosa foraging are replete with references such as "active searching for animal food" (Bowman, 1961), ". . . fed extensively on nectar from the vine Sarcostemma" (Smith et al., 1978), "a split tongue ... . resembling other pollen- or nectar-feeding birds . . . is also slightly developed in adult fuliginosa" (Lack, 1945), "Probably eats more insects than the Medium ground finch. Sometimes feeds on the shore. Removes ticks from tortoises, land and marine iguanas" (Harris, 1974). Our data on fuliginosa foraging on Daphne (Boag \& Grant, 1984) included 35.3\% on "insects", $29.3 \%$ on flowers, buds, leaves, fruit pulp and nectar, with the remaining foraging on small, soft seeds (see also P. R. Grant \& Schluter, 1983). Daphne, particularly in dry years such as 1977 , is virtually devoid of these fuliginosa foods. No obvious 'feeding refugium' appears available, there being no humid highlands into which the species could migrate (Grant \& Boag, 1980). Few evergreen or 
mid-dry-season flowering perennials are present to provide insects or nectar (e.g. Sarcostemma or Waltheria), and there is little in the way of accessible shoreline, intertidal zone, or mangroves for foraging on marine invertebrates because of the steep, undercut cliffs.

Thus fuliginosa might at best be a transient resident on Daphne, undergoing frequent extinction/emigration and recolonization. A similar situation probably holds for other small passerines not resident on Daphne but found in the arid zones of larger islands, such as the insectivorous tree finches or the yellow warbler. During relatively wet years, fuliginosa can find enough food to persist on Daphne even in the dry season. However, periodically severe dry seasons would have diminished the chances of a fuliginosa population remaining alive on Daphne long enough for selection to have had the opportunity to mould a slightly larger, more granivorous phenotype. If already present, G. scandens would have made this adjustment even harder for fuliginosa, by excluding them from dry season resources such as Opuntia flowers and nectaries. The fact that the two-species combination of fuliginosa-scandens is not observed in the Galápagos substantiates this suggestion. The less arid conditions on Los Hermanos, with no Opuntia and hence no scandens, as well as the presence of additional perennials not found on Daphne (e.g. Nolana, Alternanthera), presumably permitted fuliginosa to colonize these islets and survive long enough for selection to 'fine-tune' their morphology to local conditions.

Given this hypothetical history, and accepting that Daphne does not have the ideal habitat for fuliginosa, at least one individual survived the harsh 1977 conditions there, and thus it remains surprising there are so few individuals even in good years, and virtually no breeding males. One possibility is that incoming fuliginosa now have to vie with a relatively high density of larger fortis and scandens already present on Daphne, for food, shelter and territories. At any given time, the resident Daphne species together feed heavily on most of the foods preferred elsewhere by fuliginosa. The poor visual species discrimination by Daphne fortis males may also lead them to treat fuliginosa males as conspecifics (Ratcliffe, 1981), making it difficult for the latter to establish territories on the island (P. R. Grant \& Schluter, 1983). All of the successful fortis-fuliginosa pairs have involved fuliginosa females, supporting the suggestion that male fuliginosa are at a disadvantage during the Daphne breeding season. Thus our tentative conclusion is that because of its rainfall regime and abundance of Opuntia, Daphne is host to a scandens-fortis community which cannot be readily invaded by fuliginosa (cf. Diamond, 1975). The only other fortis-scandens community is on Champion-near-Floreana, but no size shift is evident there, either because local conditions do not favour a change, or because the island is too close to Floreana for a distinctive population to evolve.

\section{Why are Daphne fortis small?}

Given that fortis were more likely to persist on Daphne than were fuliginosa, why should Daphne fortis have become smaller? To answer this question we first ask why larger finches, such as magnirostris or large fortis, do not prosper on Daphne today. We do this by looking at large seed feeding in some detail, and then integrate these findings with other data to provide a scheme for the evolution of the Daphne fortis phenotype.

As discussed earlier, magnirostris and Santa Cruz fortis have been sighted on 
Daphne, but do not remain on the island long or breed there. There are few quantitative census data available to dispel the notion that fuliginosa, fortis, scandens, and magnirostris have similar breeding habitat requirements (Sammalisto, 1966). Certainly low islands such as Genovesa, with only an arid zone, support large numbers of breeding magnirostris (P. R. Grant \& B. R. Grant, 1980a). Nor does it seem likely that Daphne is so small or magnirostris territories so large that the island is incapable of supporting a viable breeding population of the species. And in this case, we know that even brownplumaged magnirostris are aggressively dominant to male fortis and scandens on Daphne (Boag, 1981).

Part of the answer to why large fortis and magnirostris are absent may lie in the low diversity of large, hard seeds on Daphne; our feeding data for Daphne magnirostris (see Boag \& Grant, 1984) show that 54\% of all their feeding was on hard seeds $\sqrt{\mathrm{DH}} \geqslant 4.0)$, mostly Tribulus cistoides. But apart from a short-lived flush of Bursera seeds at the end of the wet season, Tribulus is the only really large, hard seed on Daphne, and the largest Daphne fortis can feed on it, albeit not as efficiently as magnirostris (see Grant, 1981b and Table 10). There are no seeds on Daphne which can only be exploited by magnirostris, such as Cordia lutea; with a $\sqrt{\mathrm{DH}}$ index of 13.73 , this seed is $50 \%$ larger and harder than Tribulus. The dry season diet of Genovesa magnirostris consists of over $25 \%$ Cordia seed feeding (P. R. Grant \& B. R. Grant, 1980a), and most islands larger than Daphne have several species of very large seed, including Cordia, Castela galapageia, Prosopis juliflora, Opuntia megasperma etc. (Abbott et al., 1977; B. R. Grant \& P. R. Grant, 1982). We know nothing about the long-term abundance or reliability of Tribulus crops on Daphne; because the species has been in the Galápagos for under 300 years, it may still be in a state of evolutionary and biogeographical flux, and sensitive to changes in climate, insect pests, or disease (Porter, 1967; P. R. Grant, 1981b).

Table 10 summarizes some of the accumulated knowledge of large seed feeding in the Geospiza. Our handling times for Opuntia, Bursera and Cordia are average times for a finch to pick up, crack and consume one seed completely. Times for Cordia are taken from P. R. Grant \& B. R. Grant (1980a) and B. R. Grant \& P. R. Grant (1982) and for Tribulus from P. R. Grant (1981b). Tribulus seeds are covered by a woody mericarp, from which finches extract one to five seeds. A conservative estimate of fortis extraction rates is three seeds from two mericarps in $107 \mathrm{~s}$, while magnirostris may get four seeds from two mericarps in $48 \mathrm{~s}$ (P. R. Grant, 1981b). The main point is that large finches, such as magnirostris, are at a tremendous energetic advantage when they forage on very large seeds such as Cordia. Softer seeds, such as Bursera, can be eaten quite rapidly by magnirostris, but larger fortis, with their lower metabolic needs, approach the net intake rates of magnirostris. Indeed the unique, strong positive allometry of bill depth in $G$. fortis (Boag, 1984) may represent an adaptation granting large fortis access to magnirostris-type seeds, while minimizing the metabolic cost of increased body size.

Data from feeding experiments conducted with captive Geospiza (unpublished), as well as other studies (Kear, 1962; Willson, 1971, 1972), suggest that large finches may eat soft seeds as fast or faster than small finches. Schluter (1982a) found the same trend under more natural conditions on Isla Pinta. But in the real world the combined search and handling time for small 
Table 10. Feeding on four large seeds by three Geospiza species

\begin{tabular}{|c|c|c|c|c|}
\hline & Opuntia & Bursera. & Tribulus & Cordia \\
\hline \multicolumn{5}{|l|}{ Seed characteristics } \\
\hline Total seed (mericarp) weight (mg) & 12.68 & 48.28 & 29.09 & 80.80 \\
\hline Seed kernel weight (mg) & 4,15 & 17.58 & 2.58 & 28.16 \\
\hline Seed kernel energy (cal) & 25.67 & 108.59 & 15.96 & 174.00 \\
\hline Seed (mericarp) diameter $(\mathrm{mm})$ & 1.91 & 3.96 & 2.89 & 5.75 \\
\hline Seed (mericarp) cross-sectional area $\left(\mathrm{mm}^{2}\right)$ & 2.87 & 12.32 & 6.56 & 25.97 \\
\hline Secd (mericarp) hardness (kgf) & 5.55 & 4.76 & 28.06 & 31.15 \\
\hline seed (mericarp) $\sqrt{\mathrm{DH}}$ index & 3.25 & 4.34 & 8.68 & 13.38 \\
\hline \multicolumn{5}{|l|}{ G. fortis feeding } \\
\hline Mean total handling time $(\mathrm{s})$ & 38.58 & 180.80 & 107.00 & - \\
\hline Kernel yield ( $\mathrm{mg} / \mathrm{min})$ & 6.46 & 5.83 & 4.35 & - \\
\hline Kernel yield $(\mathrm{cal} / \mathrm{min})$ & 32.91 & 36.02 & 26.85 & - \\
\hline D.E.B. in seeds (Nos) & 396.45 & 93.72 & 637.64 & $\ldots$ \\
\hline D.E.B. in handling time (h) & 4.25 & 4.71 & 6.05 & - \\
\hline \multicolumn{5}{|l|}{ G. scandens feeding } \\
\hline Mean total handling time (s) & 30.93 & - & - & -- \\
\hline Kernel yield ( $\mathrm{mg} / \mathrm{min}$ ) & 8.06 & - & - & $一$ \\
\hline Kernel yield (cal/min) & 49.78 &..- & - & \\
\hline D.E.B. in seeds (Nos) & 468.00 & - & - & - \\
\hline D.E.B. in handling time (h) & 4.02 & -- & -- & - \\
\hline \multicolumn{5}{|l|}{ G. magnirostris feeding } \\
\hline Mean total handling time $(\mathrm{s})$ & 12.93 & 118.24 & 48.00 & 71.60 \\
\hline Kernel yield ( $\mathrm{mg} / \mathrm{min}$ ) & 19.26 & 8.91 & 12.92 & 23.60 \\
\hline Kernel yield (cal/min) & 119.12 & 55.05 & 79.80 & 145.78 \\
\hline D.E.B. in seeds (Nos) & 604.20 & 142.83 & 971.80 & 99.00 \\
\hline D.E.B. in handling time (h) & 2.17 & 4.69 & 3.23 & 1.97 \\
\hline
\end{tabular}

Total seed weight is for fresh seeds containing complete kernels. Kernel energy is based on $6.178 \mathrm{kcal} / \mathrm{g}$ of kernel, the average for eight species given by Willson (1971). Whole seed values would be lower; $4.832 \mathrm{kcal} / \mathrm{g}$ is given for 51 whole seeds by Kendeigh \& West (1965). Seed cross-sectional area is $\pi$ (diameter/2) ${ }^{2}$. Kernel yield is based on $6.178 \mathrm{kcal} / \mathrm{g}$ as above. Daily energy budget (D.E.B.) is the average nonbreeding energy requirement of a passerine at $30^{\circ} \mathrm{C}$, with D.E.B. in kcal bird ${ }^{-1}$ day ${ }^{-1}=1.588 W^{0.67}$, where $W$ is the mean weight of a species in $\mathrm{g}$ (Kendeigh, Dol'nik \& Gavrilov, 1977). D.E.B. was $10.18 \mathrm{kcal} / \mathrm{day}$ for $16.0 \mathrm{~g}$ fortis, 12.02 for $20.5 \mathrm{~g}$ scandens, and $15.5 \mathrm{l}$ for $30.0 \mathrm{~g}$ magnirostris. "D.E.B. in seeds" is the number of kernels required to meet daily requirements and "D.E.B. in handling time" is the number of hours of seed eating per day (excluding search time) required. Based on P. R. Grant's (1981b) Tribulus handling estimates, fortis would handle 425 mericarps to procure 638 seeds, while magnirostris would handle 486 mericarps for 972 seeds.

seeds may often render them unprofitable for large birds with their higher metabolic needs. These trade-offs mean that finches of different sizes may display different types of foraging behaviour. Small finches such as small fortis or fuliginosa are always limited to the lower part of the available seed size spectrum by their morphology, and thus, except when food is superabundant, will tend to incur higher search times than larger finches. However the lower metabolic requirements of the small birds permit them to spend more time searching for the smaller seeds they can handle.

Figure 12 provides simple diagrams of these ideas. The upper diagram suggests that intrapatch foraging time is increasingly allocated to the handling of seeds as seed density increases, reducing search time (cf. Krebs, 1978: fig. 2.12). Individuals of a given size switch to a more profitable patch when the proportion of time spent eating seeds falls below some minimum level. The middle diagram suggests that small finches spend more time searching for seeds, 


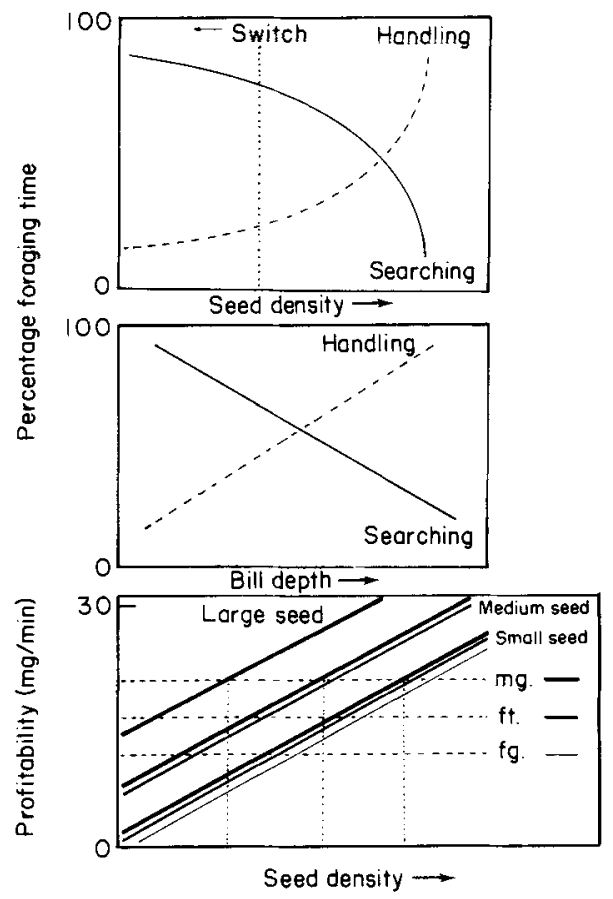

Figure 12. Qualitative models of Geospiza foraging behaviour. Lpper: For any given species, the intra-patch foraging time is increasingly allocated to seed handling as seed density increases. Middle: Larger finches spend a larger proportion of their foraging time within patches handling seeds, while small finches spend more time searching for seeds they can handle. Lower: This diagram integrates the upper two, with the three increasingly larger species fuliginosa (fg.), fortis (ft.), and magnirostris (mg.), having successively higher minimum food intakes, shown here as horizontal broken lines. In the real world, the solid diagonal lines would curve to asymptotes.

a consequence of the potentially wider diet of larger finches. The lower diagram integrates the upper two, with increasingly larger species having successively higher minimum food intake rates (cf. Newton, 1980: fig. 5). Each species has the highest profitability when eating the largest seed it can handle; for simplicity magnirostris alone is assumed to eat large seed, magnirostris and fortis medium seed, and all three small seed, probably with absolute intake rates slightly higher in larger species. The vertical dotted lines suggest that each species will have a different minimum density of each seed type for maintenance. Thus fuliginosa may be the only species to survive in an environment with low densities of only small seeds, primarily because its low metabolic demands permit it to spend a large amount of time searching for seeds of low profitability. At the same density of large seeds, magnirostris might be the only species to survive, because its unique morphology gave it access to a rate of seed intake considerably above its metabolic needs.

Thus our explanation for the reduced size of Daphne fortis stands as follows. As a low, rainshadow island, Daphne has a drier, more uncertain climate than most other Galápagos sites, producing large fluctuations in resource abundance and finch populations; coupled with the small size of the island, such fluctuations reduce the opportunities for fine resource subdivision (Diamond, 1975: fig. 44). This favoured the evolution of a single, highly opportunistic, 
essentially granivorous species (i.e. Daphne fortis). The added presence of scandens on Daphne was made possible by the unusually high density of Opuntia cactus there, and scandens's specialized feeding ecology (B. R. Grant \& P. R. Grant, 1981). Once present, the effect of scandens on fortis is twofold. In wet periods, the high diet overlap between the species must increase competition among young birds of both species. In the dry season the diets of fortis and scandens diverge, with scandens monopolizing medium size seeds. This places fortis on the horns of a dilemma; they can either try to minimize metabolic expenditure and survive on small seeds, which will be scarce if scandens has already moved on to medium seeds, or they can begin to eat large seeds such as Tribulus. This contributes to the dietary generalization seen in fortis, and the higher death rates of small birds in periods of drought. But large seed feeding on Daphne seems to be an option with limited long-term potential. The largest fortis and magnirostris have probably not been successful on Daphne because there has not been a reliable supply of foods requiring their massive beaks and attendant musculature (Bowman, 1961). The metabolic cost of the large body needed to support a large beak becomes a handicap, placing them at a competitive disadvantage with smaller fortis able to eat most of the foods available on Daphne, most of the time.

Other factors may also have favoured the evolution of a smaller Daphne phenotype. For instance, Downhower (1976) suggested that in unpredictable Galápagos environments, smaller female finches may breed more rapidly because of an enhanced ability to sequester energy reserves for egg production (Johnston \& Fleischer, 1981). Like other opportunistic species, Daphne fortis stand to gain a substantial part of their lifetime fitness in a single year of high rainfall, when finch numbers increase dramatically as pairs produce five or more broods each (Diamond, 1975; Boag \& Grant, 1984). Under crowded conditions, fortis territory sizes shrink, and food for nestlings and independent young is short (Boag, 1983; Boag \& Grant, 1984). Since young Geospiza feed only on relatively soft foods, there may again be a metabolic cost associated with larger body size. The limited data available suggest that in years with successful breeding, smaller phenotypes may survive best among immature Daphne finches, for just these reasons (Price \& Grant, 1984).

\section{CONCLUSIONS}

To proceed further than the descriptive explanations and simple qualitative models we provide here will require additional data, including time budgets showing how species apportion their time to travel between food patches, to searching within patches, and to actual processing of food items (MacArthur \& Pianka, 1966; Pyke, Pulliam \& Charnov, 1977; Krebs, 1978). We need simultaneous records of the items being taken, their relative and absolute abundances in patches and the dispersion of different patch types (Schluter, 1981, 1982a). Additional behavioural observations are needed for other reasons as well. For instance, aggressive interactions between conspecifics and between fortis and scandens need to be documented more fully, especially in the dry season. It seems unlikely that the selection favouring large and often male finches in 1977 was acting only on beak or body size, and only because of mechanical considerations related to seed feeding. Large males may also be 
dominant individuals, leading to higher fitness because of preferential access to resources such as Opuntia, seed clumps, high quality territories, or females (Morse, 1974; Baker \& Fox, 1978; Searcy, 1979; Price, 1984).

We think the Daphne fortis phenotype represents an unstable equilibrium between selection pressures favouring larger body size during droughts, because of enhanced dominance and seed-cracking ability, and selection for smaller body size during wet years, to reduce metabolic overheads, and increase reproductive output and offspring survival. The selection for smaller body size may be augmented by hybridization with fuliginosa, which could regenerate small phenotypes lost in droughts, and maintain relatively large amounts of heritable morphological variation (P. R. Grant \& Price, 1981). The dietary generalization shown by Daphne fortis in times of severe food shortage, together with their smaller size and demonstrated ability to track a changing resource base phenotypically, suggest that elements of character release are present in the Daphne situation. Thus our results support Lack's (1969) revised explanation for the character shift on Daphne to a large extent. But until more specific hypotheses are formulated, and more refined data collected to test them, it is wrong for textbooks to continue presenting the Daphne example as an unqualified case of character release. Such accounts have oversimplified the ecological complexities of the situation, complexities which in the long run may prove as interesting as has the emphasis on competition until now.

\section{ACKNOWLEDGEMENTS}

We thank L. M. Ratcliffe, B. R, Grant, K. Grant, N. Grant, D. Nakashima, E. Greene, B. Tompkins and T. D. Price for help in the field. The manuscript benefitted from the comments of L. M. Ratcliffe, G. Orians, D. Kramer, G. Bell and the reviewers.

We thank the Ecuadorean government for permission to work in the Galápagos, and particularly thank Charles Darwin Research Station (CDRS) directors C. MacFarland and H. Hoeck, and National Park Intendente M. Cifuentes, for their assistance with logistics. The other staff of the CDRS and the park were also of invaluable help, as were many local fishermen and other residents of the islands.

The work was begun while we were at McGill University, where P.R.G. was supported by a National Science and Engineering Research Council of Canada (NSERC) operating grant, and P.T.B. was supported as a graduate student by an NSERC fellowship and travel grants from the Frank M. Chapman Fund of the American Museum of Natural History. While the paper was being written, P.T.B. was supported by grants from Trent University and NSERC, and P.R.G. by grants from the U.S. National Science Foundation. P.T.B. also thanks C. M. Perrins and T. R. E. Southwood for their help and hospitality during his stay at the Edward Grey Institute.

\section{REFERENCES}

ABBOT'T, I., ABBOTT, L. K. \& GRANT, P. R., 1977. Comparative ecology of Galápagos ground finches (Geospiza Gould): Evaluation of the importance of ftoristic diversity and interspecific competition. Ecological Monographs, 47: 151-184. 
ALATALO, R. V., 1982. Bird species distributions in the Galápagos and other archipelagos: competition or chance? Ecology, 63: 881-887.

ALBRECHT, G. H., 1980. Multivariate analysis and the study of form, with special reference to canonical variate analysis. American Zoologist, 20: 679-693,

ANDREWARTHA, H. G. \& BIRCH, L. C., 1954. The Distribution and Abundance of Animals. Chicago: University of Chicago Press.

ANON., 1983. The trade winds die ... and the Queen gets a soaking. Nexe Scientist, 97: 632.

ARTHUR, W., 1982. The evolutionary consequences of interspecific competition. Advances in Ecological Research, 12: 127-187.

BAKER, M. C., 1975. Song dialects and genetic differences in white-crowned sparrows (Zonotrichia leucophrys). Evolution, 29: 226-241.

BAKER, M. C. \& FOX, S. F., 1978. Dominance, survival, and enzyme polymorphism in Dark-eyed Juncos, Junco hyemalis. Evolution, 32: 697-711.

BLACKITH, R. E. \& REYMENT, R. A., 1971. Multivariate Morphometrics. New York: Academic Press.

BOAG, P. T., 1981. Morphological variation in the Darwin's finches (Geospizinae) of Daphne Major island, Galapagos. Ph.D. thesis, McGill University, Canada.

BOAG, P. T. 1983. The heritability of external morphology in Darwin's ground finches (Geospiza $\rangle$ of Daphne Major island, Galápagos. Evolution, 37: 877-894.

BOAG, P. T., 1984. Growth and allometry of external morphology in Darwin's finches (Geospiza) on Isia Daphne Major, Galápagos. Journal of Zoology, London, in press.

BOAG, P. T. \& GRANT P. R., 1978. The heritability of external morphology in Darwin's finches. Nature, London 274: 793-794.

BOAG P. T. \& GRANT, P. R., 1981. Intense natural selection in a population of Darwin's finches (Geospizinae) in the Galápagos. Science, 214: 82-85.

BOAG, P. T. \& GRANT, P. R., 1984. Darwin's finches (Geospiza) on Isla Daphne Major, Galápagos: Breeding and feeding ecology in a climatically variable environment. Ecological Monographs 54: in press.

BOAG, P. T. \& RATCLIFFE, L. M., 1979. First record of a Blackpoll Warbler for the Galápagos islands. Condor, 81: 216-219.

BOCK, W. J., 1963. Morphological differentiation and adaptation in the Galápagos finches. Auk, 80: $202-207$.

BOWMAN, R. I., 1961. Morphological differentiation and adaptation in the Galápagos finches. University of California Publications in Zoology, 58: 1-326.

BOWMAN, R. I., 1983. The evolution of song in Darwin's finches. In A. E. Levington \& R. I. Bowman (Eds), Patterns of Evolution in Galápagos Organisms: 237-537. A.A.A.S. Special Publication No. 1. San Francisco: A.A.A.S. Pacific Division.

BOWMAN, R. I. \& BILLEB, S. L., 1965. Blood-eating in a Galápagos finch Living Bird, 4: 2944.

CARPENTER, C. C., 1966. The marine iguana of the Galápagos islands, its behaviour and ecology. Proceedings of the California Academy of Science, Series 4, 34: 329-375.

CHEKE, A. S., 1969. Mechanism and consequences of hybridization in sparrows Passer. Nature, London, 222: 179-180.

COLINVAUX, P. A., 1973. Introduction to Ecology. New York: John Wiley \& Sons.

COOK, L. M. \& O'DONALD, P., 1971. Shell size and natural selection in Cepaea nemoralis. In R. Creed (Ed.), Ecological Genetics and Evolution: 93-108. Oxford: Blackwell Scientific.

DARWIN, C., 1888. On the Origin of Species by Means of Natural Selection, or the Preservation of Favored Races in the Struggle for Life (6th edition). London: John Murray.

DHONDT, A. A., EYCKEMAN, R. \& HUBLE, J., 1979. Will Great tits become Little tits? Biological fournal of the Linnean Society, 11: 289-294.

DIAMOND, J. M., 1975. Assembly of species communities, In M. L. Cody \& J. M. Diamond (Eds.), Ecology and Evolution of Communities: 342-444. Cambridge, Mass: Belknap Press.

DIAMOND, J. M., 1978. Niche shifts and the rediscovery of interspecific competition. American Scientist, 66: 322-331.

DIXON, W. J. \& BROWN, M. B. (Eds.), 1979. BMDP-79. Biomedical Computer Programs P-Series. Berkeley: University of California Press.

DOWNHOWER, J. F., 1976. Darwin's finches and the evolution of sexual dimorphism in body size. Nature, London, 263: 558-563.

ENDLER, J. A., 1973. Gene flow and population differentiation. Science, 179: 243-250.

FEINSINGER, P. \& SWARM, L. E., 1982. "Ecological release," seasonal variation in food supply, and the hummingbird Amazilia tobaci on Trinidad and Tobago. Ecology, 63: 1574-1587.

FICKEN, M. S. \& FICKEN, R. W., 1968. Reproductive isolating mechanisms in the Blue-winged warbler-Golden-winged warbler complex. Evolution, 22: 166-179.

FORD, H. A., EWING, A. W. \& PARKIN, D. T., 1974. Blood proteins in Darwin's finches. Comparative Biochemistry and Physiology, 47B: 369-375.

FORD, H. A., PARKIN, D. T. \& EWING, A. W., 1973. Divergence and evolution in Darwin's finches. Biological Journal of the Linnean Society, 5: 289-295.

GIBSON, J. B. \& THODAY, J. M., 1973. Effects of disruptive selection. X. Selective migration. Heredity, 30: 27-32. 
LL, F. B. \& MURRAY, B. G., Jr., 1972. Discrimination behaviour and hybridization of the Blue-winged and Golden-winged warblers. Evolution, 26: 282-293.

:ANT, B. R. \& GRANT, P. R., 1981. Exploitation of Opuntia cactus by birds on the Galápagos. Oecologia, Berlin, 49: 179-187.

:ANT, B. R. \& GRANT, P. R., 1982. Niche shifts and competition in Darwin's finches: Geospiza conirostris and congeners. Evolution, 36: 637-657.

:ANT, P. R., 1972. Convergent and divergent character displacement. Biological Journal of the Linnean Society, 4: 39-68.

ANT, P. R., 1981a. Speciation and the adaptive radiation of Darwin's finches. American Scientist, 69: 653-663

:ANT, P. R., 1981 b. The feeding of Darwin's finches on Tribulus cistoides (L.) seeds. Animal Behaviour, 29. 785-793.

:ANT, P. R., 1983a. The role of interspecific competition in the adaptive radiation of Darwin's finches. In A. Levinton \& R. I. Bowman (Eds.), Patterns of Evolution in Galápagos Organisms: 187-199. A.A.A.S. Special Publication No. 1. San Francisco: A.A.A.S. Pacific Division.

.ANT, P. R., 1983b. Past and present climatic fluctuations on the Galápagos islands and their influence on Darwin's finches. Ornithological Monographs, in press.

ANT, P. R. \& ABBOTT, I., 1980. Interspecific competition, null hypotheses and island biogeography. Evolution, 34: 332-341.

:ANT, P. R. \& BOAG, P. T., 1980. Rainfall on the Galápagos and the demography of Darwin's finches. Auk, 97: 227-244.

:ANT, P. R. \& GRANT, B. R., 1980a. The breeding and feeding characteristics of Darwin's finches on Isla Genovesa, Galápagos. Ecological Monographs, 50: 381-410.

:ANT, P. R. \& GRANT, B. R., 1980b. Annual variation in finch numbers, foraging and food supply on Isla Daphne Major, Galápagos. Oecologia, Berlin, 46: 55-62.

AN'T, P. R. \& PRICE, T. D., 1981. Population variation in continuously varying traits as an ecological genetics problem. American Zoologist, 21: 795-811.

ANT, P. R. \& SCHLUTER, D. 1983. Interspecific competition inferred from patterns of guild structure. In D. R. Strong, D. S. Simberloff \& L. G. Abele (Eds), Ecological Communities: Conceptual Issues and the Evidence. Princeton, N.J.: Princeton University Press.

ANT, P. R., SMITH, J. N. M., GRANT, B. R., ABBOTT, I. J. \& ABBOTT, L. K., 1975. Finch numbers, owl predation and plant dispersal on Isla Daphne Major, Galápagos. Oecologia, Berlin, 19. 239-257.

:ANT, P. R., GRANT, B. R., SMITH, J. N. M., ABBOTT, I. J. \& ABBOTT, L. K., 1976. Darwin's finches: population variation and natural selection. Proceedings of the National Academy of Science, U.S.A., 73. 257-261.

ANT, P. R., BOAG, P. T. \& SCHLUTER, D., 1979. A bill color polymorphism in young Darwin's finches. $A u k, 96: 800-802$.

:ANT, P. R., PRICE, T. D. \& SNELL, H. 1980. The exploration of Isla Daphne Minor. Noticias de Galápagos, 31: 22-27

IGEN, D. W. \& GILBERTSON, L. G., 1973. Selective predation and the intensity of selection acting upon the lateral plates of three-spine sticklebacks. Heredity, 30 273-287.

ILLETT, J. G. \& PIMM, S. L., 1979. Direct estimation of competition. American Naluralist, 113: 593-600. IRRIS, M. P., 1973. The Galápagos avifauna. Condor, 75: 265-278.

IRRIS, M. P., 1974. A Field Guide to the Birds of the Galápagos. London: Collins.

iNDRICKSON, J. A., Jr., 1981. Community-wide character displacement re-examined. Evolution, 35 : 794-810.

JRN, H. S. \& MAY, R. M., 1977. Limits to similarity among coexisting competitors. Nature, London, 270 : $660-661$.

JRLBERT, S. H., 1978. The measurement of niche overlap and some relatives. Ecology, 59: 67-77.

, N., 1976. Karyotypic analysis of Danwin's finches, M. Sc. thesis, San Francisco State University.

HNSTON, R. F. \& FLEISCHER, R. C., 1981. Overwinter mortality and sexual size dimorphism in the house sparrow, Auk, 98: 503-511.

:AR, J. 1962. Food selection in finches with special reference to interspecific differences. Procedings of the Zoological Society of London, 138: 163-204.

iNDEIGH, S. G., DOL'NIK, V. R. \& GAVRILOV, V. M., 1977. Avian energetics. In J. Pinowski \& S. C. Kendeigh (Eds.), Granivorous Birds in Ecosystems: 127-204. Cambridge: Cambridge University Press.

iNDEIGH, S. C. \& WEST, G. C., 1965. Caloric values of plant seeds eaten by birds. Ecology, 46: 553-555. (EBS, J. R., 1978. Optimal foraging: decision rules for predators. In J. R. Krebs \& N. B. Davies (Eds.), Behavioural Ecology-An Evolutionary Approach: 23-63. Sunderland, Mass.: Sinauer Associates.

،CK, D., 1945. The Galápagos finches (Geospizinae): A study in variation. Occasional Papers of the California Academy of Science, 21: 1-159.

CK, D., 1947. Darwin's Finches. Cambridge: Cambridge University Press.

.CK, D., 1969. Subspecies and sympatry in Darwin's finches. Evolution, 23: 252-263.

.WLOR, L. R., 1980. Overlap, similarity, and competition coefficients, Ecology, 61: 245-251. 
MACARTHUR, R. \& LEVINS, R., 1967. The limiting similarity, convergence, and divergence of coexisting species. American Naturalist, 101: 377-385

MACARTHUR, R. H. \& PIANKA, E. R., 1966. On optimal use of a patchy environment. American Naturalist, 100: 603-609.

MACFARLAND, C. G. \& REEDER, W. G., 1974, Cleaning symbiosis involving Galápagos tortoises and two species of Darwin's finches. Zeitschift fur Tierpsychologie, 34: 464-483.

MCPHAIL, J. D., 1969. Predation and the evolution of a Stickleback (Gasterosteus). Journal of the Fisheries Research Board of Canada. 26: 3183-3208.

MILLER, R. S., 1967. Pattern and process in competition. Advances in Ecological Research, 4: 1-74.

MORSE, D. H., 1974. Niche breadth as a function of social dominance. American Naturalist, 108: $818-830$.

NEWTON, I., 1980. The role of food in limiting bird numbers. Ardea, 68: 11-30.

O'DONAL.D, P., 1970. Change of fitness by selection for a quantitative character. Theoretical Population Biology, 1: 219-232.

O'DONALD, P., 1973. A further analysis of Bumpus' data: the intensity of natural selection. Evolution, 27 : 398-404.

ODUM, E. P., 1971. Fundamentals of Ecology (3rd edition). Toronto: W. B. Saunders Co.

PIANKA, E. R., 1978. Evolutionary Ecology (2nd edition). New York: Harper and Row.

POLANS, N. O., 1975. Enzyme polymorphisms in species of Darwin's finches. M.Sc. thesis, San Francisco State University.

PORTER, D. M., 1967. Another Tribulus adventive in the New World. Rhodora, 69: 455-456

PRICE, T. D., 1984. Sexual selection on body size, territory and plumage variables in a population of Darwin's finches. Evolution 38; 329-341.

PRIGE, T. D. \& GRANT, P. R., 1984. Life history traits and natural selection for small body size in a population of Darwin's finches. Evolution 38: in press.

PRICE, T. D. \& MILLINGTON, S. J., 1982. Birds on Daphne Major. Noticias de Galapagos, 35: $25-27$.

PULLIAM, H. R., 1975. Coexistence of sparrows: A test of community theory. Science, 189: 474-476.

PYKE, G. H., PULLIAM, H. R. \& CHARNOV, E. L., 1977. Optimal foraging: A selective review of theory and tests. Quarterly Review of Biology, 52: 137-154.

RACINE, C. H. \& DOWNHOWER, J. F., 1974. Vegetation and reproductive strategies of Opuntia (Cactaceae) in the Galápagos islands. Biotropica, 6: 175-186.

RATCLIFFE, L. M., 1981. Species recognition in Darwin's Ground finches (Geospiza, Gould). Ph.D. thesis, McGill University, Canada.

RATCLIFFE, L. M. \& GRANT, P. R., 1983a. Species recognition in Darwin's finches (Geospiza, Gould). I. Discrimination by morphological cues. Animal Behaviour, 31: 1139-1153.

RATCLIFFE, L. M. \& GRANT, P. R., 1983b. Species recognition in Darwin's finches (Geospiza, Gould). II. Geographic variation in mate preference. Animal Behaviour, 31: II54-1165.

RICKLEFS, R. E., 1973. Ecology. Newton, Massachusetts: Chiron Press.

RIDGEWAY, R., 1897. Birds of the Galápagos archipelago. Proceedings of the U.S. National Museum, 19: $459-670$.

ROHWER, S. A., 1972. A multivariate assessment of interbreeding between the meadowlarks, Sturnella. Systematic Zoology, 21: 313-338.

ROTENBERRY, J. T, 1980. Dietary relationships among shrubsteppe passerine birds: competition or opportunism in a variable environment? Ecological Monographs, 50: 93-110.

ROUGHGARDEN, J., 1972. Evolution of niche width. American Naturalist, 106: 683-718.

ROUGHGARDEN, J., 1979. Theory of Population Genetics and Evolutionary Ecology: An Introduction. New York: Macmillan.

SAMMALISTO, L., 1966. Censusing Darwin's finches. Noticias de Galápagos, 7-8: 13-17.

SCHLUTER, D., 1981. Does the theory of optimal diets apply in complex environments? American Naturalist, 118: $139-147$.

SCHLUTER, D., 1982a. Seed and patch selection by Galápagos ground finches: relation to foraging efficiency and food supply. Ecology, 63: 1504-1517

SCHLUTER, D., 1982b. Distribution of Galápagos ground finches along an altitudinal gradient: the importance of food supply. Ecology, 63: 1106-1120.

SCHUELER, F. W. \& RISING, J. D., 1976. Phenetic evidence of natural hybridization. Systematic Zoology, 25: 283-289.

SEARCY, W. A, 1979. Morphological correlates of dominance in captive male red-winged blackbirds. Condor, 81: $417-420$.

SELANDER, R. K, 1962. Feeding adaptations in Darwin's finches. Evolution, 16: 391-393.

SIMBERLOFF, D. \& BOECKLEN, W., 1981. Size ratios and competition. Evolution, 35: 1206-1228.

SIMPSON, G. G. \& BECK, W. S., 1965. Life. An Introduction to Biology. New York: Harcourt, Brace and World, Inc.

SLATKIN, M., 1980. Ecological character displacement. Ecology, 61: 163-177.

SMITH, J. N. M., GRANT, P. R., GRANT, B. R., ABBOTT, I. J. \& ABBOTT, L. K., 1978. Seasonal variation in feeding habits of Darwin's Ground finches. Ecology, 59: 1137-1150.

SNOW, D. W., 1966. Moult and the breeding cycle in Darwin's finches. Journal fur Ornithologie, 107: $283-291$. 
SOULÉ, M., 1971. The variation problem: the gene-flow-variation hypothesis. Taxon, 20:37-50.

SOULÉ, M. \& STEWART, B. R., 1970. The "niche-variation" hypothesis: A test and alternatives. American Naturalist, 104: 85-97.

SPIETH, P. T., 1979. Environmental heterogeneity: a problem of contradictory selection pressures, gene flow, and local polymorphism. American Naturalist, 113: 247-260.

STRONG, D. R., Jr. \& SIMBERLOFF, D. S., 1981. Straining at gnats and swallowing ratios; character displacement. Evolution, 35: 810-812.

STRONG, D. R., Jr., SZYSKA, L. A. \& SIMBERLOFF, D. S., 1979. Tests of community-wide character displacement against null hypotheses. Evolution, 33: 897-913.

SWARTH, H, S., 1931. The avifauna of the Galápagos islands. Occasional Papers of the California Academy of Science, No. 18.

VAN VALEN, L., 1965. Morphological variation and width of ecological niche. American Naturalist, 99: 377-390.

VAN VALEN, L. \& GRANT, P. R., 1970. Variation and niche width reexamined. American Naturalist, 104: 587-590.

WELTY, J. C., 1975. The Life of Birds. Philadelphia: W. B. Saunders Co.

WHITTAKER, R. H., 1960. Vegetation of the Siskiyou Mountains, Oregon and California. Ecological Monographs, 30: 279-338.

WHITTAKER, R. H., 1972. Evolution and measurement of species diversity. Taxon, 21: 213-251.

WIGGINS, I. L. \& PORTER, D. M., 1971. Flora of the Galapagos Islands. Stanford, Calif.: Stanford University Press.

WILliamSON, M., 1981. Island Populations. Oxford: Oxford University Press.

WILLSON, M. F., 1971. Seed selection in some North American finches. Condor, 73: 415-429.

WILLSON, M. F., 1972. Seed Size preference in finches. Wilson Bulletin, 84: 449-455.

WILSON, E. O. \& BOSSERT, W. H., 1971. A Primer of Population Biology. Stamford, Conn.: Sinauer Associates.

YANG, S. V. \& PATTON, J. L., 1981. Genic variability and differentiation in the Galápagos finches. Auk, 98: 230-242.

YEATON, R. I. \& CODY, M. L., 1974. Competitive release in island song sparrow populations. Theoretical Population Biology, 5: 42-58. 
